\title{
NEW HYBRID FMADM MODEL FOR MOBILE COMMERCE IMPROVEMENT
}

\author{
Shu-Kung HU ${ }^{1}$, James J. H. LIOU ${ }^{2}$, Yen-Ching CHUANG ${ }^{3}$, Gwo-Hshiung TZENG ${ }^{*}$ \\ ${ }^{1}$ Kainan University, Department of Business and Entrepreneurial Management, \\ No.1, Kainan Road, Luzhu District, Taoyuan City 33875, Taiwan \\ ${ }^{2,3}$ National Taipei University of Technology, Industrial Engineering and Management, \\ No.1, Section 3, Chung-Hsiao East Road, Da'an District, Taipei City 10608, Taiwan \\ ${ }^{4}$ National Taipei University, Graduate Institute of Urban Planning, College of Public Affairs, \\ No.151, University Road, San Shia District, New Taipei City 23741, Taiwan
}

Received 09 September 2016; accepted 08 April 2017

\begin{abstract}
Internet of things (IoT) can provide an extensive scope of services via smart devices to promote the convenience of life. With advances being made in smart phones, enterprises are increasingly considering expanding their customer base through mobile commerce services. To promote $\mathrm{m}$-commerce improvement, enterprises should organize an excellent $\mathrm{m}$-commerce environment and attempt to realize user needs in the era of IoT. In a fuzzy environment of the real world, objective decision-making for m-commerce improvement is usually a FMADM problem involving feedback-effect and interdependence among the dimensions and criteria. But, many traditional decision models cannot conduct the complicated interrelationships among dimensions and criteria. This study proposes an improvement model that can promote m-commerce improvement towards achieving the aspiration level in fuzzy environment. The proposed hybrid model conducts the feedback-effect and dependence among attributes, and it combines the FDEMATEL technique, FDANP, and MFGRA methods. The empirical case study was conducted to prove the utility of the new hybrid FMADM model in evaluating an m-commerce environment. Comparative results exhibited that the proposed approach is superior to the traditional method and that it can obtain most real grey relational degree that can be used for establishing the best performance improvement strategy in reality.
\end{abstract}

Keywords: Internet of things (IoT), mobile commerce improvement, fuzzy multiple attribute decision-making (FMADM), fuzzy DEMATEL-based analytic network process (FDANP), modified fuzzy gray relation analysis (MFGRA).

JEL Classification: C00, C02, C18, C50, C61, D70, M10.

${ }^{\star}$ Corresponding author. E-mail: ghtzeng@gm.ntpu.edu.tw 


\section{Introduction}

Internet of things (IoT) can provide an extensive scope of services via smart phones to promote the convenience of life. With recent technological advances, enterprises are increasingly considering expanding their customer base through mobile commerce (called m-commerce) services for aiding decision-making tasks in the era of IoT (Maity, Dass 2014; Ruan, Shi 2016). In particular, with the advancement in wireless and mobile technologies and smart phones (such as appearing iphone $3 \mathrm{G}$ to XS with continuous improvement until now), business communities and industries operating through $\mathrm{m}$-commerce have emerged. Notably, $\mathrm{m}$ commerce can enable innovation and create business opportunities because of speedy market growth and the large number of smart phone users in Asia (Chong 2013a). Therefore, the importance of $\mathrm{m}$-commerce is increasing. To promote $\mathrm{m}$-commerce improvement, enterprises how should create an excellent $\mathrm{m}$-commerce environment and attempt to realize consumer/ user needs. In a fuzzy environment, objective decision-making for m-commerce improvement is usually a fuzzy multiple-attribute decision-making (FMADM) problem involving interdependence and feedback-effect among all considering factors such as dimensions and criteria. However, many traditional decision models cannot conduct the complicated interrelationships in the real world problems.

To address the aforementioned situations, this study used the new hybrid FMADM model that combined the fuzzy decision-making trial and evaluation laboratory (FDEMATEL) technique, an FDEMATEL-based analytic network process (FDANP), and the modified fuzzy grey relation analysis (MFGRA) methods to consider the interdependence and feedback between dimensions or criteria. The FDEMATEL technique was used to build the fuzzy total influence relation matrix for addressing the interrelationship among dimensions or criteria, and to build a fuzzy influence network relationship map (FINRM) for providing systematic improvement. The fuzzy total influence relation matrix also was used with the basic concepts of the analytic network process (ANP) for developing the fuzzy influence weights of fuzzy DEMATEL-based ANP (called FDANP). The MFGRA method was combined with the fuzzy influence weights as weighting to integrate each performance coefficient of grey relation from each criterion into grey-relational degree in each dimension and overall towards closing the aspiration level, and to assess priority improvement for m-commerce (problem-solving) on the basis of grey-relational degrees and FINRM. The traditional method adopting the concept of "max-min" as a benchmark only can be used for the selection and ranking, cannot be used for the performance improvement. The proposed model, which involves the use of an aspiration level as a benchmark, can be used to not only overcome the drawbacks of the traditional method but also can determine how improve the performance to increase the grey relational degrees towards reaching the aspiration level for each criterion, dimension, and overall performance of each alternative. The proposed model can also use in only single alternative for problem-solving in performance improvement. Simon $(1955,1972)$ explained the concept of aspiration level, according to which the decision-makers should set the aspiration level as a benchmark to choose a satisfied alternative. Simon combined this concept into his work and acquired the Nobel Prize in Economics in 1978. In the current study, three methods were combined to construct the new hybrid FMADM model for $\mathrm{m}$-commerce improvement. 
Eventually, the empirical case study was conducted to prove the utility of the new hybrid FMADM model. The results exhibited that Yahoo shopping (alternative $A$ ) achieve the best ranking and best selection and can also effectively make the improvement plan by systematics for Yahoo shopping (alternative $A$ ) how towards approximating the aspiration level based on the FINRM. Furthermore, the comparative results exhibited that the new hybrid FMADM model is superior to the traditional model and that it can achieve most real grey relational degree to innovate and establish the best improvement strategy in reality. The proposed model can also effectively assist enterprises promote $\mathrm{m}$-commerce improvement by enhancing "perceived security", thereby more satisfying consumer/user needs.

The rest of this article is organized as follows. The Section 1 presents the study attributes for $\mathrm{m}$-commerce improvement in the literature review. The Section 2 presents the evolution of hybrid FMADM model for facilitating m-commerce improvement. The Section 3 describes the empirical case study for showing the effectiveness of this study. Eventually, conclusions and remarks are described in the last Sections.

\section{Review of attributes for $\mathbf{m}$-commerce improvement}

The literature review begins with a discussion on $\mathrm{m}$-commerce improvement, which is the focus of this study. Subsequently, for examining m-commerce improvement, "trust", "attitude", and "perceived security" are used as the study framework on the basis of the conceptual foundation of the appropriate literature and investigations as pretest questionnaires. The details are explained in the following subsections.

\subsection{M-commerce in the era of IoT}

IoT-related technologies, such as wireless sensor networks, mobile communication networks and the Internet are applied in many areas of modern life to promote quality of service, security and convenience (Gubbi et al. 2013). Ruan and Shi (2016) proposed an IoT-based framework for monitoring fruit electronic commerce (e-commerce) deliveries to construct a perfect supply chain system in fruit e-commerce for reducing transportation time and cost via IoT-related technologies and concepts. M-commerce can be regarded as the diffusion of e-commerce, and it has developed on the basis of acceptance of technology, consumer behaviour, and extension of its applications and services (Ngai, Gunasekaran 2007). $\mathrm{M}$-commerce is a technical advancement and is an attractive domain for study because of its potential applications, novelty, and speedy expansion (Sadeh 2002). For business to consumer (B2C) markets, $\mathrm{m}$-commerce is expected to enable innovation and establish more commerce chances because of the feature of mobility (Barnes 2002; Lu et al. 2015). Mobility means easy and convenient, for example, the users can carry out instant business activities via smart device (i.e., smart phone) of IoT. Atzori et al. (2010) indicated that IoT-related technologies must include with respect to the management of the trust and security for all the exchanged data. In the era of IoT, new security infrastructure is necessary for the success of IoT. In other words, security is critical to the service-applications and physical devices of IoT (Li et al. 2016). The current study explored the evaluation attributes on the basis of the questionnaire replications and appropriate literature and suggested that the dimensions of trust, 
attitude, and perceived security can influence consumer willingness to utilize m-commerce. Consumer trust is expected to influence consumer usage intention of online shopping (Gefen et al. 2003; Gefen, Straub 2004; Fang et al. 2014). The acceptance of information technology (IT) or online usage intention can be explained by considering attitudes (Davis et al. 1989; Davis 1989; Venkatesh et al. 2003). Security also influences the consumer usage intention of m-commerce or electronic payment transactions (Chellappa, Pavlou 2002; Suh, Han 2003; Leu et al. 2015). Therefore, this study used the aforementioned the dimensions of trust, attitude, and perceived security to assess $\mathrm{m}$-commerce improvement.

\subsection{Dimension of trust}

Trust is regarded as a catalyst of market transactions and leads to customers having high anticipations of sufficing commerce relations. IT also supports commerce activity of customers in online shopping (Gefen et al. 2003; Fang et al. 2014). On the basis of prior conceptualizations of trust, we used four types of trust antecedents - honesty, competence, benevolence, and familiarity - to assess trust in m-commerce. Each criterion and its attributes can be explained as follows. Honesty is the anticipation, which the other party can make sincere agreements, for example, being truthful and achieveing commitments (McKnight, Chervany 2001; McKnight et al. 2002; Ridings et al. 2002). The honesty of a mobile vendor decreases the social uncertainty involved in breaking contracts and leads to the expected outcomes of the consumers (Gefen 2002; Gefen, Straub 2004). Therefore, honesty can be a major criterion of trust and be used to examine behavioural intention for using $\mathrm{m}$-commerce. Competence is the faith, which the other party has the technical abilities to complete its duties (McKnight, Chervany 2001; Ridings et al. 2002). Enough competence of a mobile vendor leads to goods and services being provided to customers (Gefen 2002; Gefen, Straub 2004). Accordingly, competence can also be a major criterion of trust. Benevolence is the anticipation, which the other party will show concern for the consumer. Benevolence reflects a special relationship between a vendor and the consumer, and the benevolence of a mobile supplier enhances the consumer satisfaction and service quality (McKnight, Chervany 2001; Ridings et al. 2002; Gefen, Straub 2004). Accordingly, benevolence also can be a major criterion of trust. Familiarity is a feeling produced from prior interactions and experiences, and it reduces social uncertainty through incremented comprehension (Gefen 2000; McKnight, Chervany 2001; Gefen et al. 2003). Consumer familiarity influences behavioural intention because it involves understanding the vendor (Gefen, Straub 2004; Gefen et al. 2008). Accordingly, familiarity can also be a major criterion of trust.

\subsection{Dimension of attitude}

Attitude is described as a personal feelings or cogitations about showing some behaviours (Ajzen 1991). In the current study, attitude indicates consumer' feelings about utilizing mcommerce technologies for their intended purchase. Past studies have discovered a powerful relation between customers' positive attitudes and behavioural intentions to use computer technologies (Yang 2005; Chong 2013b). Therefore, it is expected that customers' favourable attitudes before purchase will be directly related to their intentions to utilize $\mathrm{m}$-commerce technologies. The current study decomposed attitude in the environment of $\mathrm{m}$-commerce 
use into perceived ease of use, perceived usefulness and compatibility (Taylor, Todd 1995). Perceived ease of use is the degree of user perception that utilizing an IT system will be easy (Davis et al. 1989; Davis 1989). Perceived usefulness is the degree of user felling that utilizing an IT system will promote their own performance. Compatibility is the degree to which technology adopted matches the needs, tasks and of values the user (Taylor, Todd 1995). Perceived ease of use, perceived usefulness and compatibility were the most constantly evaluated criteria in the diffusion and adoption of Internet-based technologies (Liao et al. 1999; Vijayasarathy 2004; Pynpoo, van Braak 2014). Accordingly, they are regarded as major criteria of attitude when examining usage intention or adopting $\mathrm{m}$-commerce.

\subsection{Dimension of perceived security}

Perceived security has been considered as the perception that in electronic transactions, fraudulent activities will be prevented, consumer privacy will be protected, and m-commerce will be encouraged (Tsiakis, Sthephanides 2005; Kim et al. 2010; Leu et al. 2015). Gubbi et al. (2013) indicated that three physical components of IoT (i.e., RFID, wireless sensor networks and cloud) are vulnerable to attack. Security is critical to any network and encryption is an important line of defense for preventing data corruption. On the basis of prior conceptualizations of security, we used four types of authentication, encryption, data integrity, and privacy protection to examine customers' perceptions of security in $\mathrm{m}$-commerce. Authentication assures that the identities of both parties participating in an online transaction will be confirmed. The authentication mechanism typically involves a digital signature and certificate (Chellappa, Pavlou 2002; Suh, Han 2003). Encryption means that original information will be transformed into an encoded form. The encryption mechanism involves the integration of complex algorithms and keys (Aldridge et al. 1997; Chellappa, Pavlou 2002; Suh, Han 2003). Data integrity assures that data in online transmissions are not modified or deleted unlawfully. A data integrity mechanism involves using appropriate transmission technology (Suh, Han 2003; Tsiakis, Sthephanides 2005). Privacy protection assures that information concerning consumers participating in an online transaction will not be exhibited to unauthorised people (Chellappa, Pavlou 2002; Suh, Han 2003). Accordingly, these mechanisms influence security perceptions, and they can be considered major criteria for perceived security to examine usage intention.

Consequently, in the current study, the research framework is based on the conceptualisations of the investigations of pretest questionnaires and aforesaid literature, requires the selection of dimensions and criteria, as illustrated in Figure 1.

\section{Research methodology}

This Section introduces a new hybrid FMADM model that combines the FDEMATEL technique (FINRM), an FDANP, and MFGRA methods. The model can address complicated relationships involving interdependence and feedback for $\mathrm{m}$-commerce improvement. The FDEMATEL technique was used to build the FINRM and find out the fuzzy influence weights of the FDANP. Subsequently, the fuzzy influence weights were used with weighting the MFGRA methods to integrate each criterion into dimensions and overall grey relational degree. The model was used to innovate and create improvement plan of $\mathrm{m}$-commerce on the basis of the FINRM, as illustrated in Figure 2. 


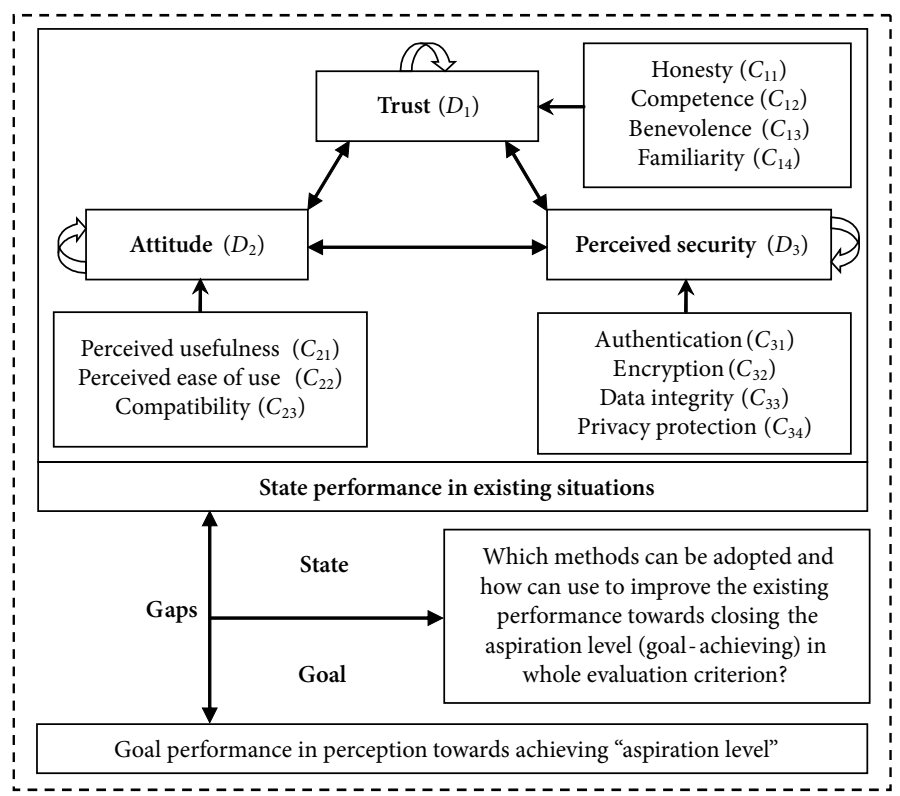

Figure 1. Research framework of m-commerce improvement

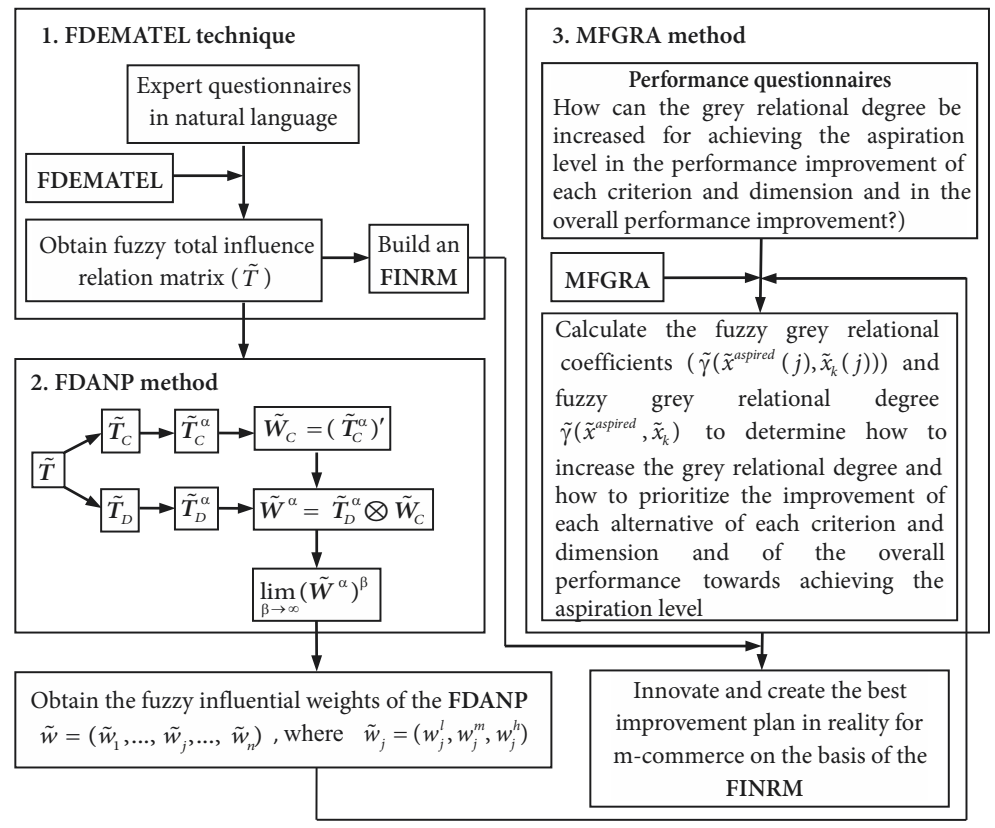

Figure 2. Hybrid FMADM model procedures 


\subsection{The concept of linguistic variable and fuzzy number}

Zadeh (1975) initiated the concept of linguistic variable to conduct the compound words of linguistic value in a natural language in real world situations. The current study used a linguistic variable to make a pairwise comparison of the FDEMATEL questionnaire. The comparison was made in terms of the options "no affect $(\tilde{0})$ ", "weak affect ( $\tilde{1})$ ", "middle affect $(\tilde{2})$ ", "strong affect $(\tilde{3})$ ", and "very strong affect $(\tilde{4})$ " as a linguistic perception (natural language). An example of a question is depicted in Figure 3. Furthermore, the linguistic variable was utilized to survey the performance score for each dimension/criterion in terms of the options "very dissatisfaction ( $\tilde{0})$ ", "dissatisfaction ( $\tilde{1})$ ", "regular $(\tilde{2})$ ", "satisfaction $(\tilde{3})$ ", and "very satisfaction $(\tilde{4})$ ".

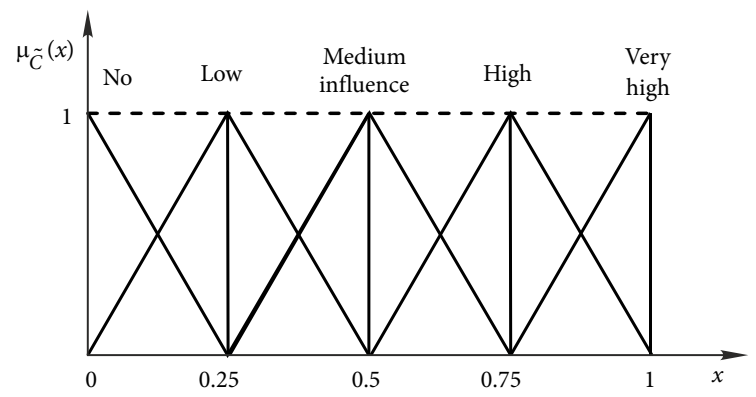

Figure 3. Membership functions of fuzzy linguistic scale (example)

This study selects the de-fuzzy method of the useful and simple to obtain the best defuzzy performance value (BDPV) of fuzzy number $\tilde{C}_{k}=\left(\tilde{C}_{k}^{l}, \tilde{C}_{k}^{m}, \tilde{C}_{k}^{h}\right)$ for $k$ alternative ( $k=1,2,3, \ldots, K)$.The BDPV can be calculated to perform the selection/ranking and innovate improvement plan as illustrated in Equation (1) (Opricovic, Tzeng 2003).

$$
\mathrm{BDPVC}_{k}=\tilde{C}_{k}^{l}+\left[\left(\tilde{C}_{k}^{h}-\tilde{C}_{k}^{l}\right)+\left(\tilde{C}_{k}^{m}-\tilde{C}_{k}^{l}\right)\right] / 3 .
$$

\subsection{Building the total fuzzy influence relation matrix using the FDEMATEL technique}

The Battelle Geneva Research Center (Gabus, Fontela 1972, 1973) developed the DEMATEL technique as a multiple attribute decision making (MADM) method for obtaining the interrelationship matrix for solving relationship problems (Tzeng, Huang 2011, 2013; Liou, Tzeng 2012; Lu et al. 2013; Liou 2013; Huang, Tzeng 2014; Hu et al. 2015; Liou et al. 2014, 2016). Similarly, the FDEMATEL technique can be also utilized to build the fuzzy relationship matrix for solving relationship problems in fuzzy environments. The FDEMATEL technique (Hsu et al. 2007; Lu et al. 2013; Hu et al. 2015) consists of the following steps.

The step one is to build a fuzzy direct relation average matrix using experts' questionnaires. The fuzzy direct relation matrix is yielded by each questionnaire, and then the fuzzy direct relation average matrix $\tilde{\boldsymbol{B}}=\left[\tilde{b}_{i j}\right]_{n \times n}=\left[\left(b_{i j}^{l}, b_{i j}^{m}, b_{i j}^{h}\right)\right]_{n \times n}$ can be acquired from the average value of the same criteria in the fuzzy direct relation matrices for all questionnaires, as illustrated in Equation (2). The linguistic scale used in this study are depicted in Table $1 ; \tilde{b}_{i j}$ 
indicates the degree of direct affect of criterion $i$ on criterion $j$, and it is determined using a measuring scale from $\tilde{0}$ to $\tilde{4}$ ("no affect $(\tilde{0})$," "weak affect $(\tilde{1})$ ), "middle affect $(\tilde{2})$ ), "strong affect $(\tilde{3})$ ", and "very strong affect $(\tilde{4})$ ”) for pair-wise comparison of criteria.

$$
\tilde{\boldsymbol{B}}=\left[\begin{array}{ccccc}
\tilde{b}_{11} & \cdots & \tilde{b}_{1 j} & \cdots & \tilde{b}_{1 n} \\
\vdots & & & & \vdots \\
\tilde{b}_{i 1} & \cdots & \tilde{b}_{i j} & \cdots & \tilde{b}_{i n} \\
\vdots & & & & \vdots \\
\tilde{b}_{n 1} & \cdots & \tilde{b}_{n j} & \cdots & \tilde{b}_{n n}
\end{array}\right] .
$$

Table 1. Membership functions for FDEMATEL questionnaire (example)

\begin{tabular}{cc}
\hline Linguistic scales of fuzzy number $\left(\tilde{b}_{i j}\right)$ & Corresponding triangular fuzzy numbers $\left(b_{i j}^{l}, b_{i j}^{m}, b_{i j}^{h}\right)$ \\
\hline No influence $(\tilde{0})$ & $(0.00,0.00,0.25)$ \\
Low influence $(\tilde{1})$ & $(0.00,0.25,0.50)$ \\
Medium influence $(\tilde{2})$ & $(0.25,0.50,0.75)$ \\
High influence $(\tilde{3})$ & $(0.50,0.75,1.00)$ \\
Very high influence $(\tilde{4})$ & $(0.75,1.00,1.00)$ \\
\hline
\end{tabular}

The step two is to build the initial fuzzy influence relation matrix $\tilde{\boldsymbol{F}}$. The fuzzy initial matrix $\tilde{\boldsymbol{F}}$ can be acquired by normalising the fuzzy matrix $\tilde{\boldsymbol{B}}$. Furthermore, the fuzzy initial matrix $\tilde{\boldsymbol{F}}$ can be acquired from Equations (3) and (4), in which the main diagonal are equal to zero.

$$
\begin{gathered}
\tilde{\boldsymbol{F}}=\tilde{\boldsymbol{B}} / s ; \\
s=\max _{i, j}\left[\max _{1 \leq i \leq n} \sum_{j=1}^{n} b_{i j}^{h}, \max _{1 \leq j \leq n} \sum_{i=1}^{n} b_{i j}^{h}\right],
\end{gathered}
$$

where $i, j=1,2, \ldots, n, \tilde{\boldsymbol{F}}=\left[\tilde{f}_{i j}\right]_{n \times n}=\left[\left(f_{i j}^{l}, f_{i j}^{m}, f_{i j}^{h}\right)\right]_{n \times n},(0,0,0) \leq \tilde{f}_{i j}<(1,1,1),(0,0,0)<\sum_{j=1}^{n} \tilde{f}_{i j}$, and $\sum_{i=1}^{n} \tilde{f}_{i j} \leq(1,1,1)$. If at least one column or row of high-side summation by a triangular fuzzy number $f_{i j}^{h}$ is equal to 1 (but not all) in $\sum_{j=1}^{n} f_{i j}^{h}$ or $\sum_{i=1}^{n} f_{i j}^{h}$, we can guarantee $\lim _{e \rightarrow \infty} \tilde{\boldsymbol{F}}^{e}=[\tilde{0}]_{n \times n}=[(0,0,0)]_{n \times n}$.

The step three is to acquire the total fuzzy influence relation matrix $\tilde{\boldsymbol{T}}$. The total fuzzy matrix $\tilde{\boldsymbol{T}}$ can be acquired from the limitless series of indirect and direct effects of the fuzzy matrix $\tilde{\boldsymbol{F}}$. In other words, the total fuzzy matrix $\tilde{\boldsymbol{T}}$ can be acquired by Equation (5), in which $\boldsymbol{I}$ is an identity matrix.

$$
\begin{aligned}
\tilde{\boldsymbol{T}} & =\tilde{\boldsymbol{F}} \oplus \tilde{\boldsymbol{F}}^{2} \oplus \tilde{\boldsymbol{F}}^{3} \oplus \tilde{\boldsymbol{F}}^{4} \oplus \ldots \oplus \tilde{\boldsymbol{F}}^{e} \\
& =\tilde{\boldsymbol{F}} \otimes\left(\boldsymbol{I} \oplus \tilde{\boldsymbol{F}} \oplus \tilde{\boldsymbol{F}}^{2} \oplus \tilde{\boldsymbol{F}}^{3} \oplus \ldots \oplus \tilde{\boldsymbol{F}}^{e-1}\right) \otimes(\boldsymbol{I} \Theta \tilde{\boldsymbol{F}}) \otimes(\boldsymbol{I} \Theta \tilde{\boldsymbol{F}})^{-1} \\
& =\tilde{\boldsymbol{F}} \otimes\left(\boldsymbol{I} \Theta \tilde{\boldsymbol{F}}^{e}\right) \otimes(\boldsymbol{I} \Theta \tilde{\boldsymbol{F}})^{-1}=\tilde{\boldsymbol{F}} \otimes(\boldsymbol{I} \Theta \tilde{\boldsymbol{F}})^{-1}, \text { when } \lim _{e \rightarrow \infty} \tilde{\boldsymbol{F}}^{e}=[\tilde{0}]=[(0,0,0)],
\end{aligned}
$$

where $\tilde{\boldsymbol{T}}=\left[\tilde{t}_{i j}\right]_{n \times n}=\left[\left(t_{i j}^{l}, t_{i j}^{m}, t_{i j}^{h}\right)\right]_{n \times n}, \boldsymbol{I}=(\boldsymbol{I} \Theta \tilde{\boldsymbol{F}}) \otimes(\boldsymbol{I} \Theta \tilde{\boldsymbol{F}})^{-1}$ and $i, j=1,2, \ldots, n$. 
The step four is to construct an FINRM based on total fuzzy matrix $\tilde{\boldsymbol{T}}$. The FINRM can help the decision-makers innovate and establish the best improvement strategy for $\mathrm{m}$-commerce through an examination of the direct/indirect influence relationship of the dimensions/criteria and the critical influence criterion. Equations (6) and (7) can be utilized to acquire the sum of each column and row of total fuzzy matrix $\tilde{\boldsymbol{T}}$; in the equations, $\tilde{x}_{i}$ indicates the fuzzy sum of the ith row of total fuzzy matrix $\tilde{\boldsymbol{T}}$ and represents the fuzzy sum of the indirect and direct effects of criterion $i$ on other criteria, $\tilde{y}_{j}$ indicates the fuzzy sum of the $j$ th column of total fuzzy matrix $\tilde{\boldsymbol{T}}$ and represents the fuzzy sum of the indirect and direct effects of other criteria on criterion $j$. When $i$ equals $j, \tilde{x}_{i} \oplus \tilde{y}_{i}$ shows an indicator of the strength of affect received and given and represents the degree of relationship that criterion $i$ plays in the problem. In addition, $\tilde{x}_{i} \Theta \tilde{y}_{i}$ represents the degree of causality among criteria: if $\tilde{x}_{i} \Theta \tilde{y}_{i}$ is negative, then criterion $i$ is affected by other criteria, and if $\tilde{x}_{i} \Theta \tilde{y}_{i}$ is positive, then criterion $i$ affects other criteria. The FINRM can be constructed from total fuzzy matrix $\tilde{\boldsymbol{T}}$.

$\tilde{\boldsymbol{x}}=\left[\tilde{x}_{i}\right]_{n \times 1}=\left[\sum_{j=1}^{n} \tilde{t}_{i j}\right]_{n \times 1}=\left[\tilde{x}_{1}, \ldots, \tilde{x}_{i}, \ldots, \tilde{x}_{n}\right]_{n \times 1}=\left[\left(x_{1}^{l}, x_{1}^{m}, x_{1}^{h}\right), \ldots,\left(x_{i}^{l}, x_{i}^{m}, x_{i}^{h}\right), \ldots,\left(x_{n}^{l}, x_{n}^{m}, x_{n}^{h}\right)\right]$

$\tilde{\boldsymbol{y}}=\left[\tilde{y}_{j}\right]_{1 \times n}^{\prime}=\left[\sum_{i=1}^{n} \tilde{t}_{i j}\right]_{1 \times n}^{\prime}=\left[\tilde{y}_{1}, \ldots, \tilde{y}_{j}, \ldots, \tilde{y}_{n}\right]_{n \times 1}=\left[\left(y_{1}^{l}, y_{1}^{m}, y_{1}^{h}\right), \ldots,\left(y_{j}^{l}, y_{j}^{m}, y_{j}^{h}\right), \ldots,\left(y_{n}^{l}, y_{n}^{m}, y_{n}^{h}\right)\right]$,

where vectors $\tilde{\boldsymbol{x}}$ and $\tilde{\boldsymbol{y}}$ indicate the sum of the vector rows and vector columns, respectively. The degrees of influence and causality can provide the decision-makers with crucial reference information that can be obtained by plotting the FINRM.

\subsection{Finding the fuzzy influence weights using the FDANP}

The DANP was developed by Tzeng and Huang (2011) on the basis of the concepts of the ANP (Saaty 1996) for use as a MADM method for solving dependence and feedback problems, and for finding the influence weights (Tzeng, Huang 2011, 2013; Liou, Tzeng 2012; Lu et al. 2013; Liou 2013; Huang, Tzeng 2014; Hu et al. 2015; Liou et al. 2014, 2016). Saaty developed the ANP to address feedback and dependence problems. How does the DANP differ from the ANP? The ANP is based on assumed relationships among dimensions and is used to obtain relative weights to achieve ranking/selection (i.e., the ANP only yields the relative best). The DANP can additionally obtain relative influence weights based on relationships. Similarly, the FDANP can also be used to address feedback and dependence problems, and to find the fuzzy influence weights in fuzzy environments for satisfying the real world situations. The FDANP method (Lu et al. 2013; Hu et al. 2015; Su et al. 2016) consists of the following steps.

The step one is to build the fuzzy unweighted supermatrix $\tilde{\boldsymbol{W}}_{C}$ from the total fuzzy matrix $\tilde{\boldsymbol{T}}$ of criteria by normalising the clustering dimension. Fuzzy matrix $\tilde{\boldsymbol{T}}_{C}$ in Equation (8), where $\sum_{j=1}^{m} m_{j}=n$ and $m<n$, is such a supermatrix. Fuzzy matrix $\tilde{\boldsymbol{T}}_{C}^{\alpha}$ can be acquired from the normalised fuzzy matrix $\tilde{\boldsymbol{T}}_{C}$, as depicted in Equation (9). Then, $\tilde{\boldsymbol{W}}_{C}$ can be acquired by transposing matrix $\tilde{\boldsymbol{T}}_{C}^{\alpha}$, as depicted in Equation (12). 


$$
\begin{aligned}
& \begin{array}{ccccc}
D_{1} & \ldots & D_{j} & \ldots & D_{m} \\
c_{11} \ldots c_{1 m_{1}} & c_{j 1} \ldots c_{j m_{j}} & c_{m 1} \ldots c_{m m_{m}}
\end{array}
\end{aligned}
$$

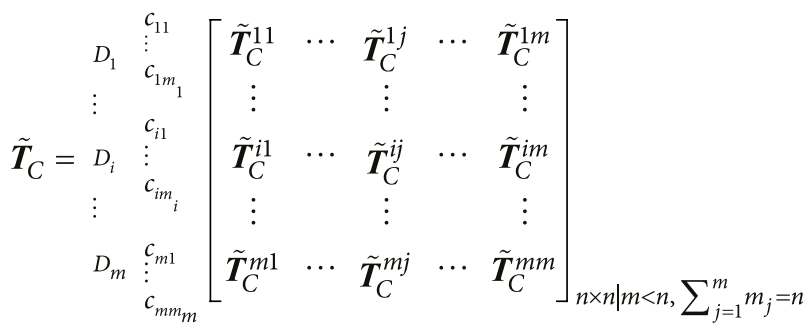

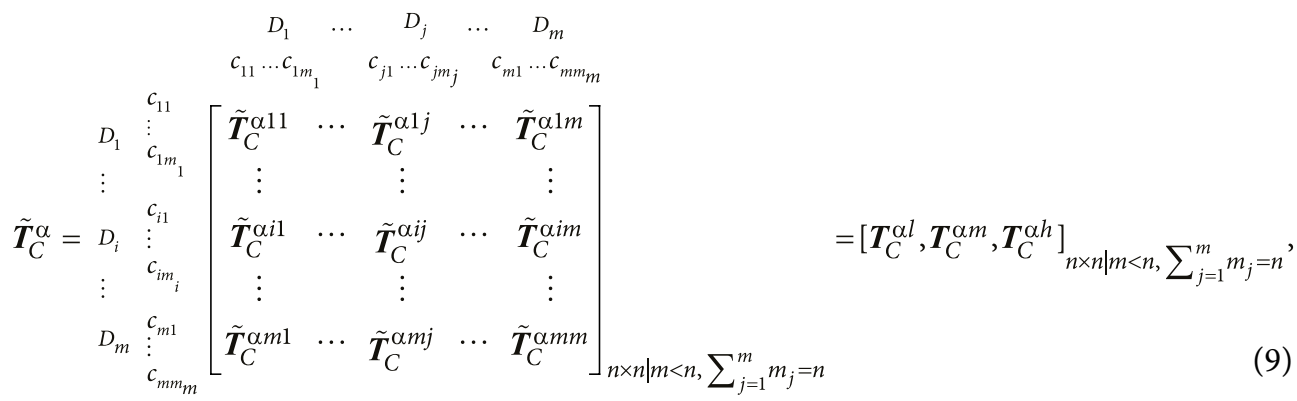

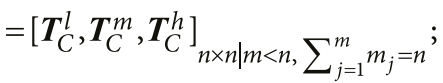

where matrix $\tilde{\boldsymbol{T}}_{C}^{\alpha 11}$ can be obtained using Equations (10) and (11). Matrix $\tilde{\boldsymbol{T}}_{C}^{\alpha m m}$ can also be obtained in a similar manner.

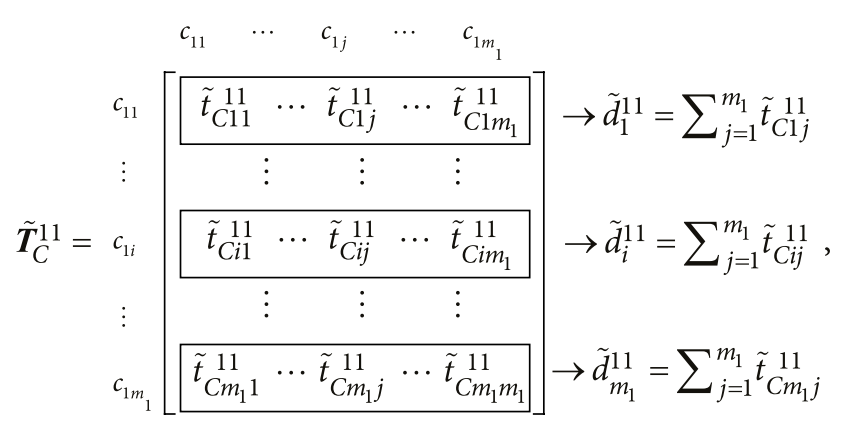

where $\tilde{d}_{i}^{11}=\sum_{j=1}^{m_{1}} \tilde{t}_{C i j}^{11}, i=1,2, \ldots, m_{1}$.

$$
\begin{gathered}
c_{11} \\
\vdots \\
\tilde{\boldsymbol{T}}_{C}^{\alpha 11}=c_{1 i} \\
\vdots \\
c_{1 m_{1}}
\end{gathered}\left[\begin{array}{ccccc}
\tilde{t}_{C 11}^{11} \varnothing \tilde{d}_{1}^{11} & \cdots & \tilde{t}_{C 1 j}^{11} \varnothing \tilde{d}_{1}^{11} & \cdots & \tilde{t}_{C 1 m_{1}}^{11} \varnothing \tilde{d}_{1}^{11} \\
\vdots & & \vdots & & \vdots \\
\tilde{t}_{C i 1}^{11} \varnothing \tilde{d}_{i}^{11} & \cdots & \tilde{t}_{C i j}^{11} \varnothing \tilde{d}_{i}^{11} & \cdots & \tilde{t}_{C i m_{1}}^{11} \varnothing \tilde{d}_{i}^{11} \\
\vdots & & \vdots & & \vdots \\
\tilde{t}_{C m_{1} 1}^{11} \varnothing \tilde{d}_{m_{1}}^{11} & \cdots & \tilde{t}_{C m_{1} j}^{11} \varnothing \tilde{d}_{m_{1}}^{11} & \cdots & \tilde{t}_{C m_{1} m_{1}}^{11} \varnothing \tilde{d}_{m_{1}}^{11}
\end{array}\right]
$$




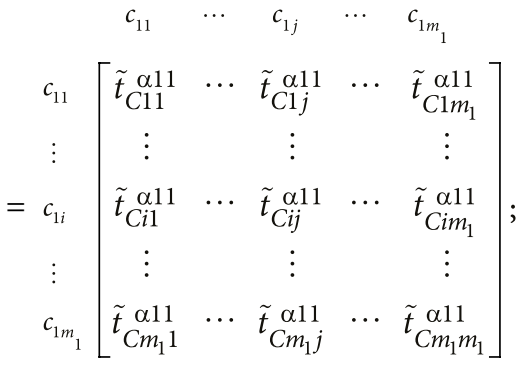

$$
\begin{aligned}
& \begin{array}{ccccc}
D_{1} & \cdots & D_{i} & \cdots & D_{m} \\
c_{11} \ldots c_{1 m} & & c_{i 1} \ldots c_{i m_{i}} & & c_{m 1} \ldots c_{m m_{m}}
\end{array}
\end{aligned}
$$

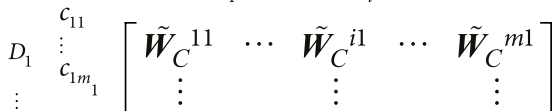

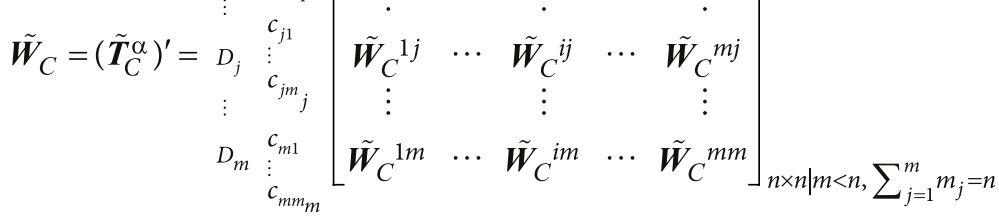

$$
\begin{aligned}
& =\left[\boldsymbol{W}_{C}^{l}, \boldsymbol{W}_{C}^{m}, \boldsymbol{W}_{C}{ }^{h}\right]_{n \times n \mid m<n}, \sum_{j=1}^{m} m_{j}=n,
\end{aligned}
$$

where matrix $\tilde{\boldsymbol{W}}_{C}^{11}$ can be obtained from Equation (13), $D_{m}$ represents the $m$ th dimension, and $c_{m m_{m}}$ represents the $m_{m}$ th criterion in the $m$ th dimension.

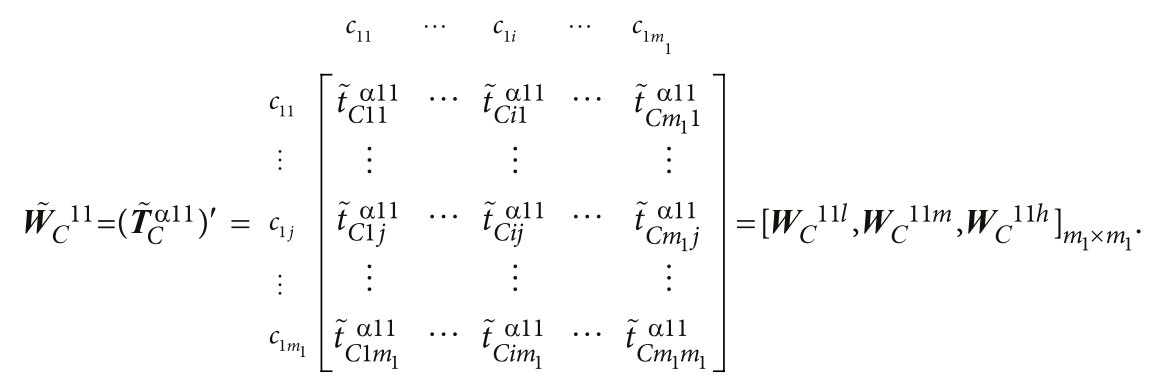

The step two is to construct the fuzzy weighted supermatrix (called the normalised supermatrix), represented by matrix $\tilde{\boldsymbol{T}}_{D}$ in Equation (14), by using the fuzzy unweighted supermatrix and the total fuzzy matrix $\tilde{\boldsymbol{T}}$ of dimensions. Fuzzy matrix $\tilde{\boldsymbol{T}}_{D}^{\alpha}$ can be acquired from by normalising fuzzy matrix $\tilde{\boldsymbol{T}}_{D}$, as illustrated in Equation (15). The normalised fuzzy matrix $\tilde{\boldsymbol{T}}_{D}^{\alpha}$ multiplier the fuzzy unweighted supermatrix $\tilde{\boldsymbol{W}}_{C}$ are utilized to acquire the fuzzy weighted supermatrix $\tilde{\boldsymbol{W}}^{\alpha}$, as illustrated in Equation (16). 


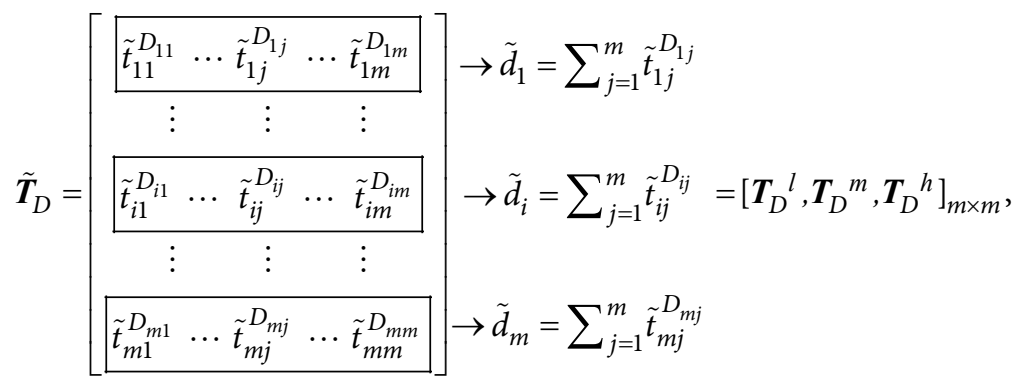

where $\tilde{d}_{i}=\sum_{j=1}^{m} \tilde{t}_{i j}^{D_{i j}}, i=1,2, \ldots, m$.

$$
\begin{aligned}
& \tilde{\boldsymbol{T}}_{D}^{\alpha}=\left[\begin{array}{ccccc}
\tilde{t}_{11}^{D_{11}} \varnothing \tilde{d}_{1} & \cdots & \tilde{t}_{1 j}^{D_{1 j}} \varnothing \tilde{d}_{1} & \cdots & \tilde{t}_{1 m}^{D_{1 m}} \varnothing \tilde{d}_{1} \\
\vdots & & \vdots & & \vdots \\
\tilde{t}_{i 1}^{D_{i 1}} \varnothing \tilde{d}_{i} & \cdots & \tilde{t}_{i j}^{D_{i j}} \varnothing \tilde{d}_{i} & \cdots & \tilde{t}_{i m}^{D_{i m}} \varnothing \tilde{d}_{i} \\
\vdots & & \vdots & & \vdots \\
\tilde{t}_{m 1}^{D_{m 1}} \varnothing \tilde{d}_{m} & \cdots & \tilde{t}_{m j}^{D_{m j}} \varnothing \tilde{d}_{m} & \cdots & \tilde{t}_{m m}^{D_{m m}} \varnothing \tilde{d}_{m}
\end{array}\right]=\left[\begin{array}{ccccc}
\tilde{t}_{11}^{\alpha_{11}} & \cdots & \tilde{t}_{1 j}^{\alpha_{1 j}} & \cdots & \tilde{t}_{1 m}^{\alpha_{1 m}} \\
\vdots & & \vdots & & \vdots \\
\tilde{t}_{i 1}^{\alpha_{i 1}} & \cdots & \tilde{t}_{i j}^{\alpha_{i j}} & \cdots & \tilde{t}_{i m}^{\alpha_{i m}} \\
\vdots & & \vdots & & \vdots \\
\tilde{t}_{m 1}^{\alpha_{m 1}} & \cdots & \tilde{t}_{m j}^{\alpha_{m j}} & \cdots & \tilde{t}_{m m}^{\alpha_{m m}}
\end{array}\right] \\
& =\left[\boldsymbol{T}_{D}^{\alpha l}, \boldsymbol{T}_{D}^{\alpha m}, \boldsymbol{T}_{D}^{\alpha h}\right]_{m \times m} ; \\
& \tilde{\boldsymbol{W}}^{\alpha}=\tilde{\boldsymbol{T}}_{D}^{\alpha} \otimes \tilde{\boldsymbol{W}}_{C} \\
& =\left[\begin{array}{cccccc}
\tilde{t}_{11}^{\alpha_{11}} \odot \tilde{\boldsymbol{W}}_{C}^{11} & \cdots & \tilde{t}_{i 1}^{\alpha_{i 1}} \odot \tilde{\boldsymbol{W}}_{C}{ }^{i 1} & \cdots & \tilde{t}_{m 1}^{\alpha_{m 1}} \odot \tilde{\boldsymbol{W}}_{C}^{m 1} \\
\vdots & & \vdots & & \vdots \\
t_{1 j}^{\alpha_{1 j}} \odot \tilde{\boldsymbol{W}}_{C}^{1 j} & \cdots & \tilde{t}_{i j}^{\alpha_{i j}} \odot \tilde{\boldsymbol{W}}_{C}{ }^{i j} & \cdots & \tilde{t}_{m j}^{\alpha_{m j}} \odot \tilde{\boldsymbol{W}}_{C}^{m j} \\
\vdots & & \vdots & & \vdots \\
\tilde{t}_{1 m}^{\alpha_{1 m}} \odot \tilde{\boldsymbol{W}}_{C}^{1 m} & \cdots & \tilde{t}_{i m}^{\alpha_{i m}} \odot \tilde{\boldsymbol{W}}_{C}^{i m} & \cdots & \tilde{t}_{m m}^{\alpha_{m m}} \odot \tilde{\boldsymbol{W}}_{C}^{m m}
\end{array}\right]_{n \times n \mid m<n, \sum_{j=1}^{m} m_{j}=n} \\
& =\left[\begin{array}{ccccc}
{\left[\tilde{\boldsymbol{W}}^{\alpha 11}\right]_{m_{1} \times m_{1}}} & \cdots & {\left[\tilde{\boldsymbol{W}}^{\alpha i 1}\right]_{m_{i} \times m_{1}}} & \cdots & {\left[\tilde{\boldsymbol{W}}^{\alpha m 1}\right]_{m_{m} \times m_{1}}} \\
\vdots & & \vdots & & \vdots \\
{\left[\tilde{\boldsymbol{W}}^{\alpha 1 j}\right]_{m_{1} \times m_{j}}} & \cdots & {\left[\tilde{\boldsymbol{W}}^{\alpha i j}\right]_{m_{i} \times m_{j}}} & \cdots & {\left[\tilde{\boldsymbol{W}}^{\alpha m j}\right]_{m_{m} \times m_{j}}} \\
\vdots & & \vdots & & \vdots \\
{\left[\tilde{\boldsymbol{W}}^{\alpha 1 m}\right]_{m_{1} \times m_{m}}} & \cdots & {\left[\tilde{\boldsymbol{W}}^{\alpha i m}\right]_{m_{i} \times m_{m}}} & \cdots & {\left[\tilde{\boldsymbol{W}}^{\alpha m m}\right]_{m_{m} \times m_{m}}}
\end{array}\right]_{n \times n \mid m<n, \sum_{j=1}^{m} m_{j}=n}
\end{aligned}
$$

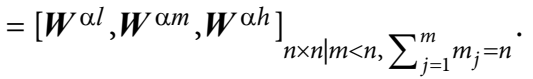

The step three is to determine the fuzzy influence weights by using the fuzzy limit weighted supermatrix (i.e., $\left.\lim _{\beta \rightarrow \infty}\left(\tilde{\boldsymbol{W}}^{\alpha}\right)^{\beta}\right)$. The fuzzy weighted supermatrix $\left(\tilde{\boldsymbol{W}}^{\alpha}\right)$ is multiplied by itself multiple times to acquire the fuzzy limit weighted supermatrix. The fuzzy influence weights (also called the FDANP weights) can then be calculated as $\lim _{\beta \rightarrow \infty}\left(\tilde{\boldsymbol{W}}^{\alpha}\right)^{\beta}$ until the 
fuzzy supermatrix converges and becomes a stable fuzzy supermatrix as illustrated in Equation (17), where $\beta$ represents a positive integer number. The fuzzy influence weights can be utilized for not only selection and ranking but also improvement towards approximating the aspiration level (i.e., the FDANP will attain the aspiration level when the fuzzy influence weights are combined with the MFGRA).

$$
\tilde{\boldsymbol{w}}=\left(\tilde{w}_{1}, \ldots, \tilde{w}_{j}, \ldots, \tilde{w}_{n}\right)=\left(\left(w_{1}^{l}, w_{1}^{m}, w_{1}^{h}\right), \ldots,\left(w_{j}^{l}, w_{j}^{m}, w_{j}^{h}\right), \ldots,\left(w_{n}^{l}, w_{n}^{m}, w_{n}^{h}\right)\right), j=1,2, \ldots, n .
$$

\subsection{Evaluating and improving performance using MFGRA}

The grey system theory was developed by Deng (1982) as a MADM method to address problems of decision-making (Chiou, Tzeng 2001; Haq, Kannan 2006; Peng et al. 2011; Kou et al. 2012; Chiu et al. 2014; Liou et al. 2016). This study improved the traditional grey relation method to replace the concept of "max-min" by using a negative point and an ideal ideal point as benchmarks in the concept of the fuzzy aspiration level and worst level (called "aspired-worst") as a benchmark for avoiding a situation that can be described by "the task of selecting the best among inferior alternatives". The MFGRA is also mathematically useful when dealing with a system with uncertain information in fuzzy environments in the real world. Therefore, we used the MFGRA to combine the fuzzy influence weights for each performance, for integrating each criterion into each dimensional performance for determining the fuzzy grey relational degree in fuzzy environments. We can subsequently improve the problems of $\mathrm{m}$-commerce by using the FINRM how to increase the fuzzy grey relational degree towards attaining/closing the aspiration level (the traditional fuzzy grey relational analysis (FGRA) can only perform for ranking and selection, the proposed new modified FGRA (called MFGRA) can not only be utilized for the selection and ranking, but also can be utilized for the performance improvement towards reaching/closing the aspiration level) on the basis of interrelationships of the feedback and dependence problem in real world situations. The MFGRA method includes the following steps.

The step one is to set the fuzzy worst levels $\left(\tilde{x}_{j}^{\text {worst }}\right)$ and fuzzy aspiration level $\left(\tilde{x}_{j}^{\text {aspired }}\right)$. In this study, scores of $\tilde{0}$ to $\tilde{4}$ (very dissatisfaction $\leftarrow \tilde{0}, \tilde{1}, \tilde{2}, \tilde{3}, \tilde{4} \rightarrow$ very satisfaction) were employed in the questionnaires by using natural language for users/customers, such as "very dissatisfaction ( $\tilde{0})$ ", "dissatisfaction $(\tilde{1})$ ", "regular $(\tilde{2})$ ", "satisfaction $(\tilde{3})$ ", and "very satisfaction ( $\tilde{4})$ ", for evaluating the performance. Hence, the fuzzy worst level was set at score as $\tilde{x}_{j}^{\text {worst }}=\left(x_{j}^{\text {worst }(l)}, x_{j}^{\text {worst }(m)}, x_{j}^{\text {worst }(h)}\right)=(0,0,0)$ and the fuzzy aspiration level was set at score as $\tilde{x}_{j}^{\text {aspired }}=\left(x_{j}^{\text {aspired }(l)}, x_{j}^{\text {aspired }(m)}, x_{j}^{\text {aspired }(h)}\right)=(4,4,4)$. The linguistic scale used in the questionnaire are depicted in Table 2.

The step two is to determine the fuzzy grey relation coefficient. The traditional and proposed fuzzy grey relation coefficient can be obtained from Equations (18) and (19), respectively.

The traditional FGRA solution:

$$
\tilde{\gamma}\left(\tilde{x}_{j}^{\max }, \tilde{x}_{k j}\right)=\frac{\min _{k} \min _{j}\left|\tilde{x}_{j}^{\max } \Theta \tilde{x}_{k j}\right| \oplus \varsigma \max _{k} \max _{j}\left|\tilde{x}_{j}^{\max } \Theta \tilde{x}_{k j}\right|}{\left|\tilde{x}_{j}^{\max } \Theta \tilde{x}_{k j}\right| \oplus \varsigma \max _{k} \max _{j}\left|\tilde{x}_{j}^{\max } \Theta \tilde{x}_{k j}\right|} .
$$


Table 2. Membership functions for MFGRA questionnaire (example)

\begin{tabular}{cc}
\hline Linguistic scales of fuzzy number $\left(\tilde{x}_{k j}\right)$ & Corresponding triangular fuzzy numbers $\left(x_{k j}^{l}, x_{k j}^{m}, x_{k j}^{h}\right)$ \\
\hline Very bad $(\tilde{0})$ & $(0.00,0.00,1.00)$ \\
Bad $(\tilde{1})$ & $(0.00,1.00,2.00)$ \\
Moderate $(\tilde{2})$ & $(1.00,2.00,3.00)$ \\
Good $(\tilde{3})$ & $(2.00,3.00,4.00)$ \\
Very good $(\tilde{4})$ & $(3.00,4.00,4.00)$ \\
\hline
\end{tabular}

The proposed MFGRA solution:

$$
\tilde{\gamma}\left(\tilde{x}_{j}^{\text {aspired }}, \tilde{x}_{k j}\right)=\frac{\min _{k} \min _{j}\left|\tilde{x}_{j}^{\text {aspired }} \Theta \tilde{x}_{k j}\right| \oplus \varsigma \max _{k} \max _{j}\left|\tilde{x}_{j}^{\text {aspired }} \Theta \tilde{x}_{k j}\right|}{\left|\tilde{x}_{j}^{\text {aspired }} \Theta \tilde{x}_{k j}\right| \oplus \varsigma \max _{k} \max _{j}\left|\tilde{x}_{j}^{\text {aspired }} \Theta \tilde{x}_{k j}\right|},
$$

where $\tilde{x}_{j}^{\max }=\max _{k}\left\{\tilde{x}_{k j} \mid k=1,2,3, \ldots, K ; j=1,2,3, \ldots, n\right\}, \tilde{x}_{k j}$ is the performance value of the $j$ th criterion in the $k$ th alternative, $\tilde{x}_{j}^{\text {aspired }}=(4,4,4)$, and $\varsigma$ is the distinguished coefficient, and $\varsigma=0.5$ in this paper.

The step three is to determine the fuzzy grey relation degree. The traditional and proposed fuzzy grey relation degree can be acquired using Equations (20) and (21), respectively.

The traditional FGRA solution: $\tilde{\gamma}\left(\tilde{x}^{\max }, \tilde{x}_{k}\right)=\sum_{j=1}^{n} \tilde{w}_{j} \otimes \tilde{\gamma}\left(\tilde{x}_{j}^{\max }, \tilde{x}_{k j}\right)$;

The proposed MFGRA solution: $\tilde{\gamma}\left(\tilde{x}^{\text {aspired }}, \tilde{x}_{k}\right)=\sum_{j=1}^{n} \tilde{w}_{j} \otimes \tilde{\gamma}\left(\tilde{x}_{j}^{\text {aspired }}, \tilde{x}_{k j}\right)$,

where $\tilde{w}_{j}$ is the fuzzy influence weight of the $j$ th criterion, obtained by using the FDANP. The fuzzy grey relational degrees can help the decision-makers innovate and establish the best improvement strategy for $\mathrm{m}$-commerce in reality (i.e., how to increase the fuzzy grey relational degrees towards approximating the aspiration level).

\section{Analysis for empirical case study of m-commerce improvement}

This section discusses analysis of empirical case study that was conducted to demonstrate the utility of the proposed approach (a hybrid modified FMADM model) for improving mcommerce in reality. The details are provided in the following Subsections.

\subsection{Problem descriptions}

With technological advancements, enterprises are increasingly considering expanding their customer base through m-commerce for supporting decision-making tasks (Maity, Dass 2014). Mobile phone use continues to increase because of advances being made in mobile marketing (Watson et al. 2013) in the era of IoT. Commercial activity involving $\mathrm{m}$-commerce has become popular because of the increase in the number of mobile devices (Chong 2013a). A major challenge is innovating and creating the best improvement plan of $\mathrm{m}$-commerce 
in reality for satisfying consumer/user needs (i.e., including the problems of vagueness or inaccurate in human cognitive processes) in Taiwan. Previous studies involving "perceived security" are scant. Most prior studies supposed the independent dimensions and criteria in hierarchic structure to obtain a comparatively good result. Decision-making for $\mathrm{m}$-commerce improvement in a fuzzy environment is essentially an FMADM problem involving interdependence and feedback among dimensions and criteria. However, many traditional decision models cannot conduct the complicated interrelationships. This paper attempted to progress a new hybrid FMADM model that could be utilized to address complex interaction problems in fuzzy environment with imprecise information for identifying the origins of a problem. Such a model can enable systematic improvement on the basis of the FINRM and help avoid "stopgap, or the so-called piecemeal, measures". Furthermore, we replaced the comparatively good result obtained from existing alternatives by the aspiration level. Finally, we compared the traditional method and the proposed new method (including modified FMADM), which the advantage of results and contributions.

\subsection{Results and analyses}

This paper built a construction of interrelationships for decision-making problem by using the FDEMATEL technique, and observed the evaluation attributes for improving mcommerce in reality. On the basis of experts' questionnaires, the fuzzy matrix $\tilde{\boldsymbol{B}}$ could be acquired. The fuzzy matrix $\tilde{\boldsymbol{F}}$ could be acquired by normalising the fuzzy matrix $\tilde{\boldsymbol{B}}$. The total fuzzy matrix $\tilde{\boldsymbol{T}}$ could be acquired using the limitless series of indirect and direct effects for the fuzzy matrix $\tilde{\boldsymbol{F}}$, as illustrated in Table 3 . The significant confidence of the questionnaires reached $98.2 \%$, more than $95 \%$ (refer to Note in Table 3, the results exhibited that 18 expert questionnaires in practical experience can also be applicated to ensure explanatory power because the empirical questionnaires in practical experience are different from the social response survey; the social response survey is necessary to investigate more samples because it include the impact of many personal attributes and social attributes). Table 3 exhibits that whole criteria have a complex interrelationship. The total fuzzy matrix $\tilde{\boldsymbol{T}}$ could be divided into a fuzzy matrix of criteria $\left(\tilde{\boldsymbol{T}}_{C}\right)$ and a fuzzy matrix of dimensions $\left(\tilde{\boldsymbol{T}}_{D}\right)$ by normalising the clustering dimensions, as illustrated in Table 4 . This Table 4 exhibits that the interrelationships among the criteria and dimensions are based on experts' cognition in practical experience and the fuzzy/de-fuzzy sum of the influences received and given for each criterion and dimension, respectively. Clearly, dimension 'trust' has the biggest positive value $\left(\tilde{x}_{i} \Theta \tilde{y}_{i}\right),(-2.390,0.046,2.511) /(0.056)$, implying that it's the most influence dimension. The 'trust' dimension plays a primary part in the improvement system and has the maximal influence on the other dimensions. The "attitude" dimension has the least value $\left(\tilde{x}_{i} \Theta \tilde{y}_{i}\right),(-2.628,-0.086,2.449) /(-0.088)$ and is therefore most readily influenced by the other dimensions. Consequently, the decision-makers are able to handle "trust" dimension as a main consideration in potential commercial activities involving m-commerce. The "perceived security" dimension has the biggest intensity of interrelationship $\left(\tilde{x}_{i} \oplus \tilde{y}_{i}\right),(2.502$, $3.880,7.289) /(4.557)$ and is therefore regarded the most significant dimension by the experts, and it has the most interactive relation with the other dimensions. On the contrary, the value of $\left(\tilde{x}_{i} \oplus \tilde{y}_{i}\right)$ for "trust" dimension is $(1.592,3.018,6.493) /(3.701)$ and therefore, the "trust" 
dimension relates the smallest to the other dimensions. In addition, the "familiarity" criterion has the biggest degree of causality $\left(\tilde{x}_{i} \Theta \tilde{y}_{i}\right),(-7.945,1.017,10.636) /(1.236)$ and therefore, it very readily influences the other criteria. The "competence" criterion has the smallest degree of causality $\left(\tilde{x}_{i} \Theta \tilde{y}_{i}\right),(-9.789,-0.701,8.208) /(-0.761)$, and hence, it is the criterion most easily affected by the other criteria. The "privacy protection" criterion with a $\left(\tilde{x}_{i} \oplus \tilde{y}_{i}\right)$ value of $(9.655,14.686,27.203) /(17.181)$ has the most significant relationship with the other criteria. On the contrary, the "benevolence" criterion has a $\left(\tilde{x}_{i} \oplus \tilde{y}_{i}\right)$ value of $(3.721,8.968,21.173) /$ (11.288) and relates the smallest to the other criteria. On the basis of Table 4, the FINRM for each dimension and their criteria can be drawn by using $\left(\tilde{x}_{i} \oplus \tilde{y}_{i}\right)$ and $\left(\tilde{x}_{i} \Theta \tilde{y}_{i}\right)$ values of dimension or criteria to illustrate the fuzzy influence network relationship; the FINRM is depicted in Figure 4. Clearly, experts exhibited that "trust" and "perceived security" dimension should be prioritised simultaneously for m-commerce improvement; lack of "trust" and "perceived security" is the source of problems and can affect the attitude dimension. From the viewpoint of the "trust" dimension, the directions of priority improvement can be ordered as "familiarity" > "honesty" > "benevolence" > "competence". The decision-makers can provide the perfect interactive environment to enhance mutual understanding with each customer, for achieving the desired performance of trust. From the viewpoint of the "perceived security" dimension, the directions of priority improvement are "encryption" > "authentication" > "privacy protection" > "data integrity". Decision-makers can provide an ideal encryption standard to achieve the desired encryption level for satisfying customers' needs.

The FDANP combines the FDEMATEL technique and the ANP and can be used to conduct a survey of a company for obtaining indicators for the interrelationship between criteria and dimensions (i.e., dependence and feedback). The FDANP could be utilized to acquire the fuzzy influence weights (i.e., fuzzy global weights) using the concepts of the ANP and Markov chain until the limit fuzzy supermatrix became a stable fuzzy supermatrix, as illustrated in Table 5. The FDANP approach can also be used to derive the fuzzy local weights from the fuzzy global weights, as depicted in Tables 6 (fuzzy values) and 7 (de-fuzzy values). This derivation helps the decision-makers determine the fuzzy influence weights of each dimension and individual criterion across three dimensions for the purpose of selection and ranking. The results exhibit that "perceived security" is the most crucial dimension and that compatibility is the most critical criterion in terms of influence.

Then, the fuzzy influence weights were combined with the MFGRA to assess the priority of performance improvement for promoting problem-solving of $\mathrm{m}$-commerce on the basis of the fuzzy grey relational degrees and FINRM. An empirical case study was conducted to evaluate the fuzzy grey relational degrees by using the proposed approach and traditional method. On the basis of performance questionnaires in Yahoo shopping (alternative $A$ ), PChome online 24 hours (alternative $B$ ), and Amazon (alternative $C$ ), the fuzzy/de-fuzzy grey relational degrees could be obtained, as depicted in Tables 6 and 7. The results exhibit that Yahoo shopping (alternative $A$ ) obtains the best ranking and selection, and Amazon (alternative $C$ ) should be prioritised for m-commerce improvement. As depicted in Table 7, for the traditional method, the grey relational degrees for Yahoo shopping (alternative $A$ ), PChome online 24 hours (alternative $B$ ), and Amazon (alternative $C$ ) are 0.973, 0.873, and 0.733 , respectively, implying the order $A>B>C$; for the proposed method, the grey relation- 
al degrees for Yahoo shopping (alternative $A$ ), PChome online 24 hours (alternative $B$ ), and Amazon (alternative $C$ ) are $0.796,0.764$, and 0.703 , respectively, also implying the result $A>$ $B>C$. The comparative results exhibit that although the ranking is the same, the proposed method is superior because it can obtain a more realistic grey relational degree, resulting in the formulation of the best improvement plan. In the proposed method, the grey relational coefficients (shown the degree of closing the aspiration level) for "trust", "attitude", and "perceived security" in Yahoo shopping (alternative $A$ ) were 0.901, 0.806, and 0.619, respectively; the values for PChome online 24 hours (alternative $B$ ) were $0.847,0.754$, and 0.628 , respectively, and those for Amazon (alternative $C$ ) were 0.718, 0.668, and 0.635, respectively. These results exhibit that "perceived security" is the first priority for m-commerce improvement because it has the least grey relational coefficient. Thus, the empirical case study shows that the proposed model can determine the actual problem-solving points in the real world how to improve the problem for promoting $\mathrm{m}$-commerce towards achieving the aspiration level.

Table 3. The fuzzy total influence relation matrix $\tilde{\boldsymbol{T}}=\left[\tilde{t}_{i j}\right]_{n \times n}=\left[\left(t_{i j}^{l}, t_{i j}^{m}, t_{i j}^{h}\right)\right]_{n \times n}$

\begin{tabular}{|c|c|c|c|c|c|c|c|c|c|c|c|}
\hline$t_{i j}^{l}$ & $C_{11}$ & $C_{12}$ & $C_{13}$ & $C_{14}$ & $C_{21}$ & $C_{22}$ & $C_{23}$ & $C_{31}$ & $C_{32}$ & $C_{33}$ & $C_{34}$ \\
\hline$C_{11}$ & 0.243 & 0.308 & 0.211 & 0.258 & 0.297 & 0.285 & 0.311 & 0.403 & 0.393 & 0.401 & 0.458 \\
\hline$C_{12}$ & 0.235 & 0.192 & 0.121 & 0.199 & 0.258 & 0.246 & 0.259 & 0.291 & 0.291 & 0.288 & 0.329 \\
\hline$C_{13}$ & 0.169 & 0.154 & 0.069 & 0.152 & 0.161 & 0.151 & 0.185 & 0.203 & 0.201 & 0.203 & 0.226 \\
\hline$C_{14}$ & 0.317 & 0.327 & 0.192 & 0.201 & 0.378 & 0.368 & 0.368 & 0.415 & 0.413 & 0.410 & 0.442 \\
\hline$C_{21}$ & 0.263 & 0.321 & 0.153 & 0.246 & 0.259 & 0.348 & 0.372 & 0.370 & 0.359 & 0.374 & 0.387 \\
\hline$C_{22}$ & 0.247 & 0.304 & 0.146 & 0.236 & 0.341 & 0.234 & 0.353 & 0.349 & 0.338 & 0.347 & 0.361 \\
\hline$C_{23}$ & 0.258 & 0.307 & 0.158 & 0.258 & 0.372 & 0.361 & 0.276 & 0.372 & 0.362 & 0.374 & 0.389 \\
\hline$C_{31}$ & 0.400 & 0.409 & 0.200 & 0.290 & 0.429 & 0.405 & 0.468 & 0.429 & 0.556 & 0.558 & 0.606 \\
\hline$C_{32}$ & 0.430 & 0.417 & 0.214 & 0.288 & 0.420 & 0.402 & 0.474 & 0.559 & 0.430 & 0.570 & 0.620 \\
\hline$C_{33}$ & 0.363 & 0.374 & 0.184 & 0.260 & 0.392 & 0.364 & 0.423 & 0.506 & 0.501 & 0.390 & 0.544 \\
\hline$C_{34}$ & 0.438 & 0.445 & 0.198 & 0.282 & 0.432 & 0.405 & 0.461 & 0.567 & 0.558 & 0.563 & 0.472 \\
\hline$t_{i j}^{m}$ & $C_{11}$ & $C_{12}$ & $C_{13}$ & $C_{14}$ & $C_{21}$ & $C_{22}$ & $C_{23}$ & $C_{31}$ & $C_{32}$ & $C_{33}$ & $C_{34}$ \\
\hline$C_{11}$ & 0.462 & 0.545 & 0.432 & 0.497 & 0.550 & 0.538 & 0.563 & 0.633 & 0.624 & 0.632 & 0.677 \\
\hline$C_{12}$ & 0.473 & 0.417 & 0.354 & 0.437 & 0.505 & 0.493 & 0.512 & 0.545 & 0.543 & 0.544 & 0.580 \\
\hline$C_{13}$ & 0.399 & 0.395 & 0.254 & 0.374 & 0.412 & 0.401 & 0.433 & 0.454 & 0.451 & 0.453 & 0.478 \\
\hline$C_{14}$ & 0.549 & 0.561 & 0.426 & 0.432 & 0.607 & 0.596 & 0.606 & 0.645 & 0.642 & 0.644 & 0.672 \\
\hline$C_{21}$ & 0.515 & 0.556 & 0.399 & 0.490 & 0.494 & 0.579 & 0.605 & 0.618 & 0.609 & 0.621 & 0.639 \\
\hline$C_{22}$ & 0.490 & 0.535 & 0.383 & 0.474 & 0.570 & 0.463 & 0.583 & 0.594 & 0.586 & 0.593 & 0.611 \\
\hline$C_{23}$ & 0.504 & 0.541 & 0.396 & 0.491 & 0.594 & 0.583 & 0.505 & 0.614 & 0.606 & 0.615 & 0.635 \\
\hline$C_{31}$ & 0.626 & 0.636 & 0.456 & 0.548 & 0.665 & 0.646 & 0.692 & 0.643 & 0.755 & 0.759 & 0.798 \\
\hline$C_{32}$ & 0.648 & 0.644 & 0.467 & 0.550 & 0.663 & 0.648 & 0.700 & 0.762 & 0.644 & 0.769 & 0.809 \\
\hline$C_{33}$ & 0.592 & 0.605 & 0.434 & 0.520 & 0.631 & 0.609 & 0.654 & 0.716 & 0.711 & 0.608 & 0.749 \\
\hline$C_{34}$ & 0.657 & 0.667 & 0.462 & 0.552 & 0.674 & 0.653 & 0.696 & 0.772 & 0.764 & 0.769 & 0.686 \\
\hline
\end{tabular}


End of Table 3

\begin{tabular}{cccccccccccc}
\hline$t_{i j}^{h}$ & $C_{11}$ & $C_{12}$ & $C_{13}$ & $C_{14}$ & $C_{21}$ & $C_{22}$ & $C_{23}$ & $C_{31}$ & $C_{32}$ & $C_{33}$ & $C_{34}$ \\
\hline$C_{11}$ & 1.010 & 1.112 & 0.960 & 1.059 & 1.144 & 1.125 & 1.175 & 1.189 & 1.181 & 1.184 & 1.220 \\
$C_{12}$ & 1.041 & 0.984 & 0.894 & 1.008 & 1.104 & 1.083 & 1.131 & 1.127 & 1.119 & 1.122 & 1.152 \\
$C_{13}$ & 0.945 & 0.954 & 0.750 & 0.919 & 0.992 & 0.974 & 1.027 & 1.019 & 1.012 & 1.015 & 1.039 \\
$C_{14}$ & 1.170 & 1.193 & 1.015 & 1.048 & 1.257 & 1.236 & 1.279 & 1.275 & 1.268 & 1.270 & 1.296 \\
$C_{21}$ & 1.118 & 1.161 & 0.971 & 1.093 & 1.116 & 1.195 & 1.249 & 1.228 & 1.216 & 1.224 & 1.243 \\
$C_{22}$ & 1.086 & 1.131 & 0.947 & 1.069 & 1.187 & 1.069 & 1.219 & 1.198 & 1.185 & 1.193 & 1.211 \\
$C_{23}$ & 1.109 & 1.149 & 0.969 & 1.095 & 1.217 & 1.196 & 1.146 & 1.225 & 1.214 & 1.222 & 1.242 \\
$C_{31}$ & 1.178 & 1.202 & 1.006 & 1.126 & 1.253 & 1.230 & 1.297 & 1.192 & 1.287 & 1.289 & 1.318 \\
$C_{32}$ & 1.191 & 1.206 & 1.013 & 1.125 & 1.250 & 1.227 & 1.298 & 1.293 & 1.186 & 1.293 & 1.322 \\
$C_{33}$ & 1.142 & 1.167 & 0.977 & 1.090 & 1.211 & 1.188 & 1.254 & 1.250 & 1.241 & 1.150 & 1.271 \\
$C_{34}$ & 1.217 & 1.237 & 1.025 & 1.144 & 1.277 & 1.253 & 1.317 & 1.318 & 1.309 & 1.313 & 1.238 \\
\hline
\end{tabular}

Note: The average consensus gap $=\frac{1}{n^{2}} \sum_{i=1}^{n} \sum_{j=1}^{n}\left(\left|t_{i j}^{p}-t_{i j}^{p-1}\right| / t_{i j}^{p}\right) \times 100 \%=1.8 \%<5 \%$, which is in accord with defuzziness; here, $n$ is the number of criteria $(n=11), p$ is the number of experts in practical experience $(p=18)$, and the significant confidence is $98.2 \%$, greater than the recommended minimal value of $95 \%$.

Table 4. The fuzzy/de-fuzzy sum of influences given/received for dimensions and criteria

\begin{tabular}{|c|c|c|c|c|}
\hline$\tilde{\boldsymbol{T}}_{D}, \tilde{\boldsymbol{T}}_{C}$ & $\tilde{x}_{i}$ & $\tilde{y}_{i}$ & $\tilde{x}_{i} \oplus \tilde{y}_{i}$ & $\tilde{x}_{i} \Theta \tilde{y}_{i}$ \\
\hline$D_{1}$ & $\begin{array}{c}(0.817,1.532,3.287), \\
1.878\end{array}$ & $\begin{array}{c}(0.775,1.486,3.207), \\
1.822\end{array}$ & $\begin{array}{c}(1.592,3.018,6.493), \\
3.701\end{array}$ & $\begin{array}{c}(-2.390,0.046,2.511) \\
0.056\end{array}$ \\
\hline$D_{2}$ & $\begin{array}{c}(0.931,1.646,3.469), \\
2.015\end{array}$ & $\begin{array}{c}(1.019,1.732,3.559), \\
2.103\end{array}$ & $\begin{array}{c}(1.950,3.378,7.028) \\
4.118\end{array}$ & $\begin{array}{c}(-2.628,-0.086,2.449), \\
-0.088\end{array}$ \\
\hline$D_{3}$ & $\begin{array}{c}(1.274,1.959,3.650) \\
2.294\end{array}$ & $\begin{array}{c}(1.227,1.920,3.639), \\
2.262\end{array}$ & $\begin{array}{c}(2.502,3.880,7.289) \\
4.557\end{array}$ & $\begin{array}{c}(-2.365,0.039,2.422) \\
0.032\end{array}$ \\
\hline$C_{11}$ & $\begin{array}{c}(3.567,6.153,12.358), \\
7.359\end{array}$ & $\begin{array}{c}(3.363,5.914,12.205), \\
7.160\end{array}$ & $\begin{array}{c}(6.930,12.067,24.562) \\
14.520\end{array}$ & $\begin{array}{c}(-8.638,0.239,8.995) \\
0.199\end{array}$ \\
\hline$C_{12}$ & $\begin{array}{c}(2.709,5.401,11.765), \\
6.625\end{array}$ & $\begin{array}{c}(3.557,6.102,12.498), \\
7.385\end{array}$ & $\begin{array}{c}(6.265,11.503,24.263) \\
14.010\end{array}$ & $\begin{array}{c}(-9.789,-0.701,8.208), \\
-0.761\end{array}$ \\
\hline$C_{13}$ & $\begin{array}{c}(1.875,4.504,10.646), \\
5.675\end{array}$ & $\begin{array}{c}(1.846,4.464,10.527), \\
5.612\end{array}$ & $\begin{array}{c}(3.721,8.968,21.173), \\
11.288\end{array}$ & $\begin{array}{c}(-8.652,0.040,8.800), \\
0.063\end{array}$ \\
\hline$C_{14}$ & $\begin{array}{c}(3.831,6.381,13.307), \\
7.840\end{array}$ & $\begin{array}{c}(2.671,5.364,11.777), \\
6.604\end{array}$ & $\begin{array}{c}(6.502,11.746,25.083) \\
14.444\end{array}$ & $\begin{array}{c}(-7.945,1.017,10.636), \\
1.236\end{array}$ \\
\hline$C_{21}$ & $\begin{array}{c}(3.451,6.125,12.814), \\
7.463\end{array}$ & $\begin{array}{c}(3.740,6.364,13.009), \\
7.704\end{array}$ & $\begin{array}{c}(7.191,12.489,25.822) \\
15.167\end{array}$ & $\begin{array}{c}(-9.558,-0.239,9.074), \\
-0.241\end{array}$ \\
\hline$C_{22}$ & $\begin{array}{c}(3.257,5.881,12.494), \\
7.211\end{array}$ & $\begin{array}{c}(3.570,6.208,12.775), \\
7.518\end{array}$ & $\begin{array}{c}(6.827,12.090,25.269) \\
14.729\end{array}$ & $\begin{array}{c}(-9.518,-0.327,8.924), \\
-0.307\end{array}$ \\
\hline$C_{23}$ & $\begin{array}{c}(3.487,6.086,12.784), \\
7.452\end{array}$ & $\begin{array}{c}(3.951,6.549,13.393), \\
7.964\end{array}$ & $\begin{array}{c}(7.438,12.635,26.177) \\
15.416\end{array}$ & $\begin{array}{c}(-9.906,-0.463,8.833), \\
-0.512\end{array}$ \\
\hline$C_{31}$ & $\begin{array}{c}(4.750,7.225,13.378), \\
8.451\end{array}$ & $\begin{array}{c}(4.462,6.996,13.313), \\
8.257\end{array}$ & $\begin{array}{c}(9.212,14.221,26.691) \\
16.708\end{array}$ & $\begin{array}{c}(-8.563,0.228,8.916) \\
0.194\end{array}$ \\
\hline
\end{tabular}


End of Table 4

\begin{tabular}{ccccc}
\hline$\tilde{\boldsymbol{T}}_{D}, \tilde{\boldsymbol{T}}_{C}$ & $\tilde{x}_{i}$ & $\tilde{y}_{i}$ & $\tilde{x}_{i} \oplus \tilde{y}_{i}$ & $\tilde{x}_{i} \Theta \tilde{y}_{i}$ \\
\hline \multirow{2}{*}{$C_{32}$} & $(4.824,7.305,13.404)$, & $(4.400,6.935,13.218)$, & $(9.224,14.239,26.622)$, & $(-8.394,0.370,9.004)$, \\
& 8.511 & 8.184 & 16.695 & 0.327 \\
$C_{33}$ & $(4.302,6.828,12.943)$, & $(4.478,7.008,13.276)$, & $(8.780,13.836,26.218)$, & $(-8.974,-0.179,8.464)$, \\
& 8.024 & 8.254 & 16.278 & -0.230 \\
$C_{34}$ & $(4.820,7.351,13.650)$, & $(4.835,7.335,13.553)$, & $(9.655,14.686,27.203)$, & $(-8.732,0.016,8.815)$, \\
& 8.607 & 8.574 & 17.181 & 0.033 \\
\hline
\end{tabular}

Table 5. The fuzzy/de-fuzzy influential weights obtained from the steady-state super-matrix

\begin{tabular}{|c|c|c|c|c|}
\hline Criteria & $C_{11}$ & $C_{12}$ & $C_{13}$ & $C_{14}$ \\
\hline $\begin{array}{l}\text { The influential } \\
\text { weights }\end{array}$ & $\begin{array}{c}(0.055,0.078,0.100) \\
0.078\end{array}$ & $\begin{array}{c}(0.059,0.081,0.103) \\
0.081\end{array}$ & $\begin{array}{c}(0.030,0.059,0.086) \\
0.059\end{array}$ & $\begin{array}{c}(0.045,0.071,0.097) \\
0.071\end{array}$ \\
\hline Criteria & $C_{21}$ & $C_{2}$ & & $C_{23}$ \\
\hline $\begin{array}{l}\text { The influential } \\
\text { weights }\end{array}$ & $\begin{array}{c}(0.091,0.112,0.137) \\
0.113\end{array}$ & $\begin{array}{r}(0.087,0.11 \\
0.1\end{array}$ & $\begin{array}{l}09,0.135,) \\
10\end{array}$ & $\begin{array}{c}0.095,0.116,0.141) \\
0.117\end{array}$ \\
\hline Criteria & $C_{31}$ & $C_{32}$ & $C_{33}$ & $C_{34}$ \\
\hline $\begin{array}{l}\text { The influential } \\
\text { weights }\end{array}$ & $\begin{array}{c}(0.090,0.093,0.095), \\
0.093\end{array}$ & $\begin{array}{c}(0.088,0.091,0.095) \\
0.091\end{array}$ & $\begin{array}{c}(0.090,0.092,0.095) \\
0.092\end{array}$ & $\begin{array}{c}(0.097,0.097,0.097) \\
0.097\end{array}$ \\
\hline
\end{tabular}

\subsection{Discussions and implications}

Figure 4 illustrates the fuzzy influence analyses of dimensions and criteria, and the fuzzy/ de-fuzzy grey relational degrees are depicted in Tables 6 and 7. The information can help the decision-makers in actual decision-making. In Figure 4, the eleven criteria and three dimensions could be readily depicted to affect each other. The results for the three dimensions exhibit that 'trust' dimension, with the biggest positive value $\left(\tilde{x}_{i} \Theta \tilde{y}_{i}\right)$, is the most influence dimension as the priority of performance improvement. Trust is the origin of the problem, and it is followed by "perceived security" (positive value) and "attitude" (negative value). "Familiarity", with the biggest positive value $\left(\tilde{x}_{i} \Theta \tilde{y}_{i}\right)$ in the "trust" dimension, is the most influence criterion as the improvement priority. It is followed by "honesty" (positive value), "benevolence" (positive value), and "competence" (negative value). On the basis of Tables 6 and 7, "perceived security", which has the best ranking, is the most crucial dimension in terms of influence, and it is followed by "attitude" and "trust". "Privacy protection" shows the best ranking in the "perceived security" dimension, and it is the most critical criterion in terms of influence. It is followed by "authentication", "data integrity", and "encryption". The results exhibit that "privacy protection" in "perceived security" with positive value $\left(\tilde{x}_{i} \Theta \tilde{y}_{i}\right)$ have a significant and positive relationship to affect $\mathrm{m}$-commerce adoption. In other words, if the enterprises can ensure the data privacy and security of the customers, it can acquire the potential customers and keep the customers in m-commerce market. 


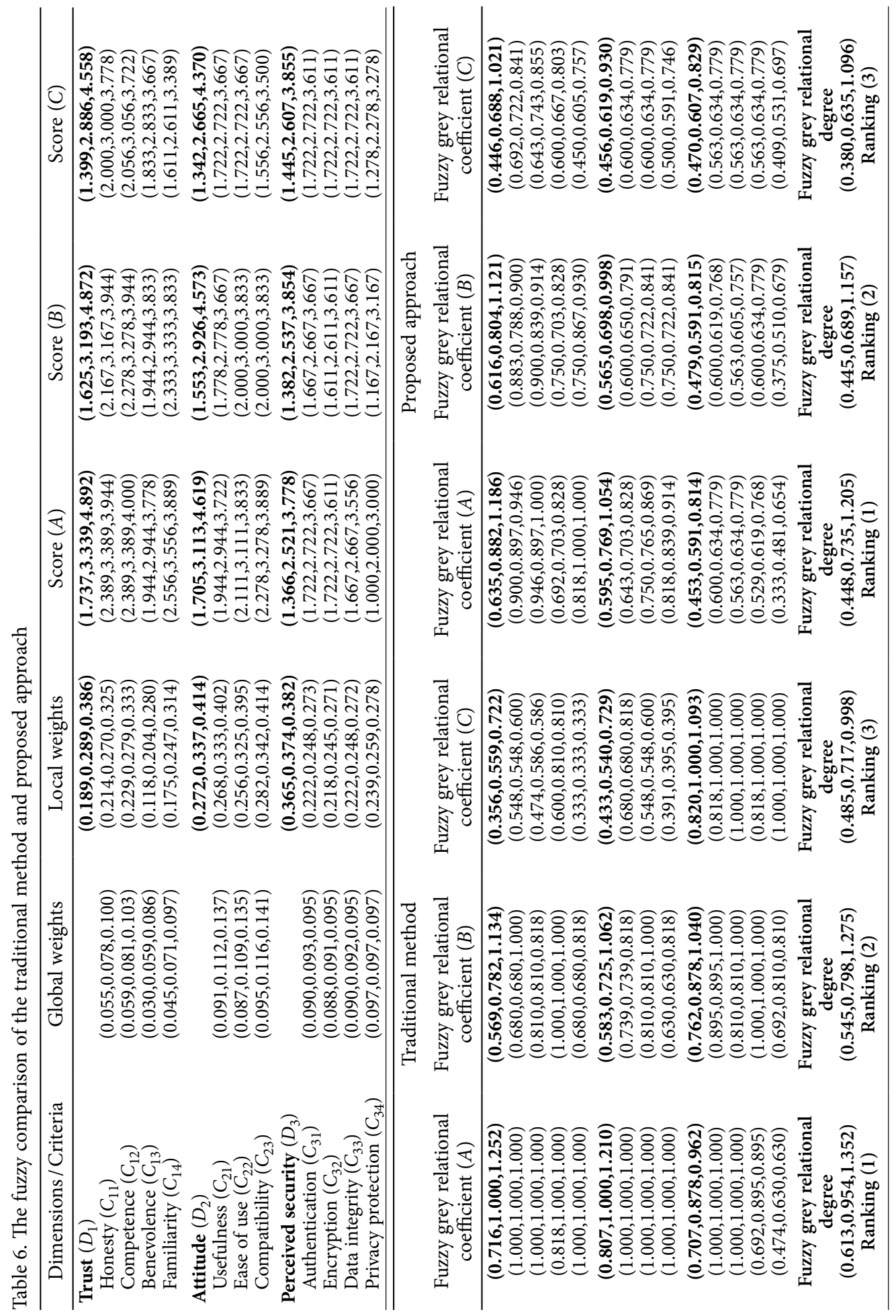




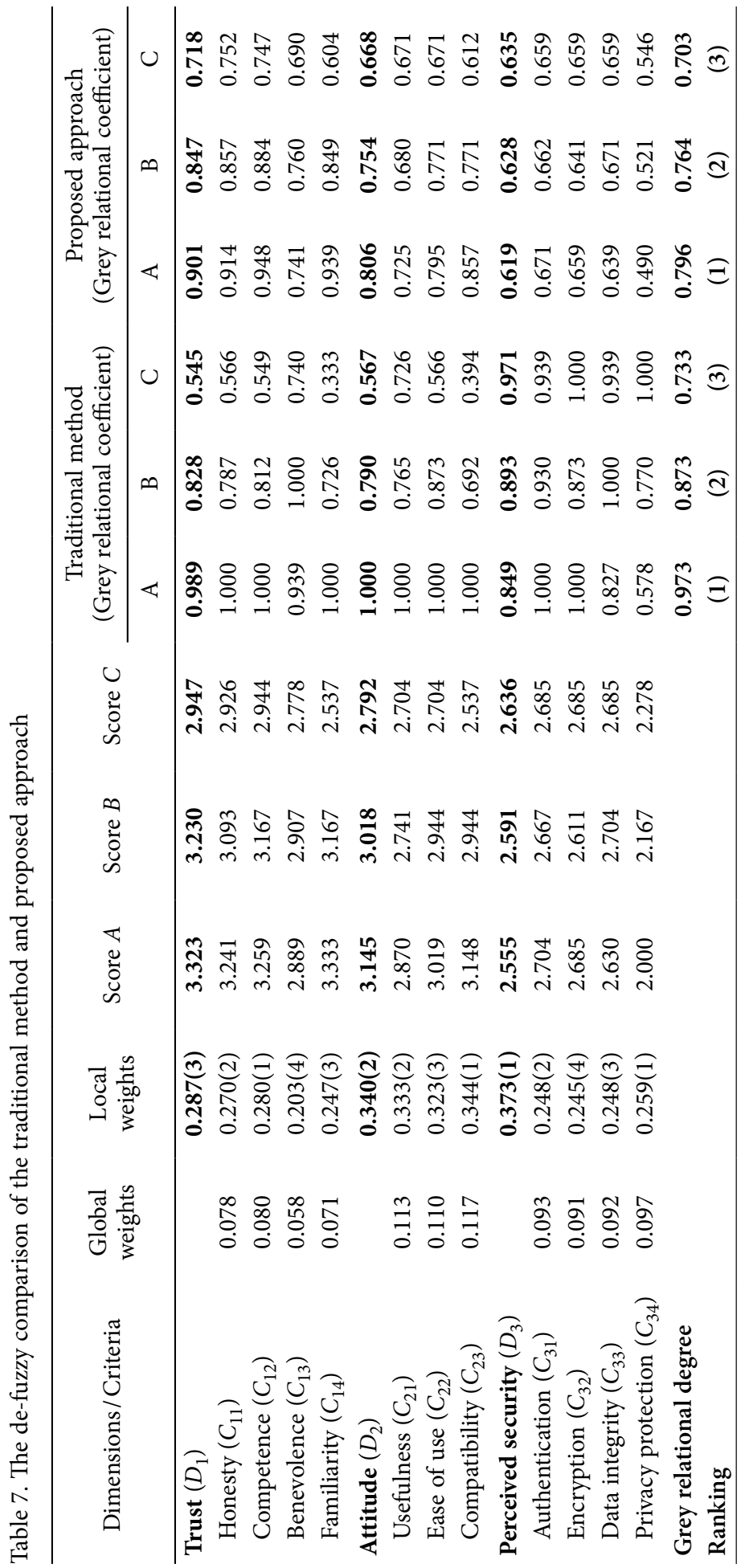




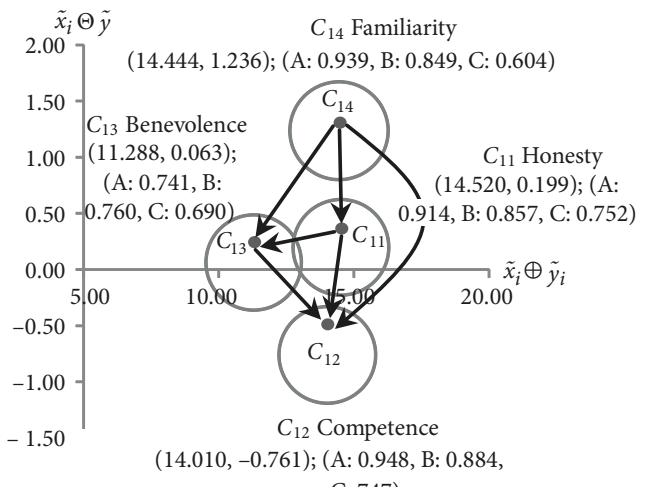

C: 747)
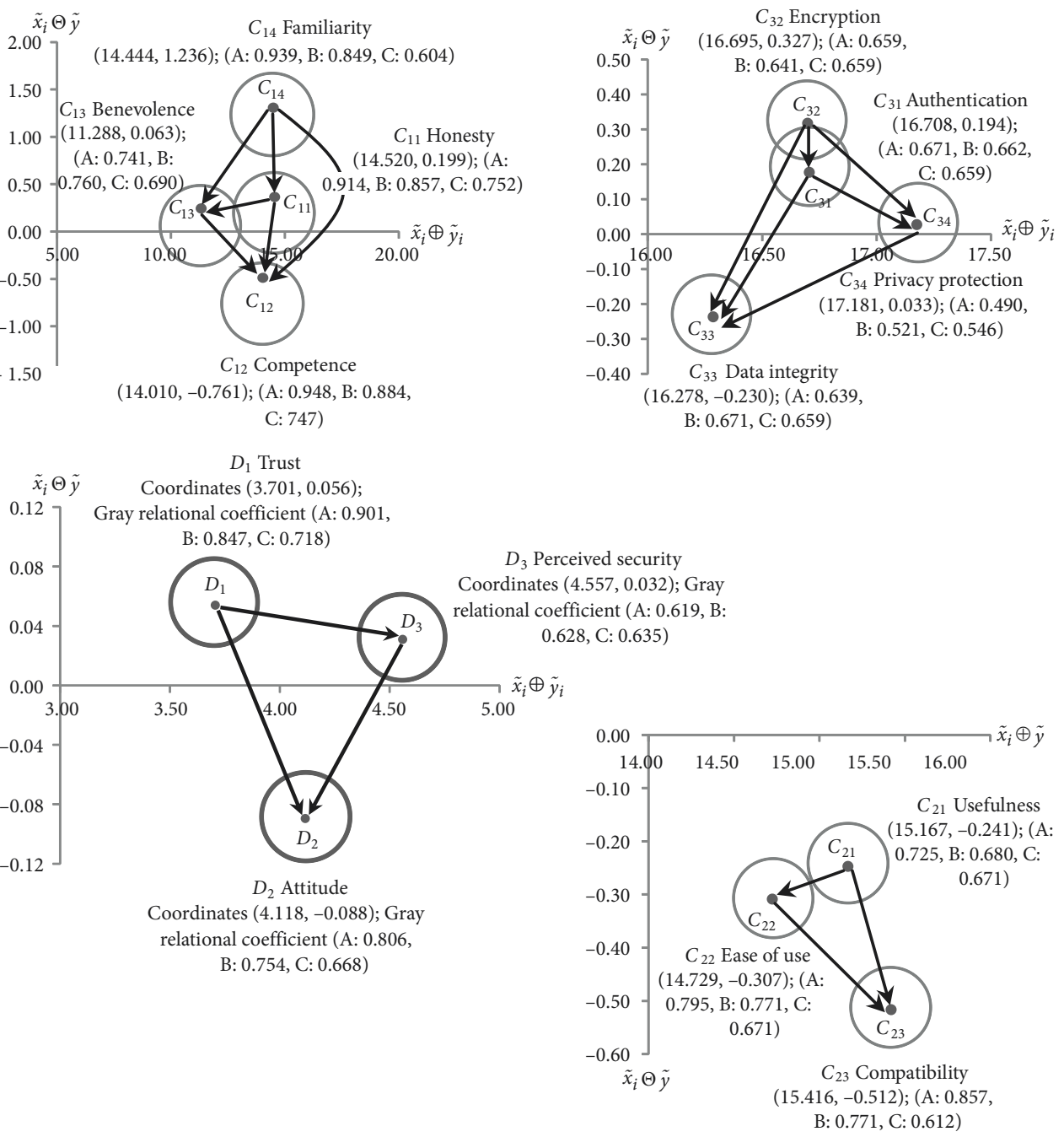

Figure 4. Fuzzy influential network relationship map for systematic improvement in three alternatives

To address the problem of a fuzzy environment with uncertain information, the fuzzy influence weights can be combined with the MFGRA for evaluating the fuzzy/de-fuzzy grey relational degrees, to determine the improvement priority. The fuzzy performance scores should then be replaced with the fuzzy grey relational degrees that exhibit the improvement direction, which is more relevant in the present rival environment. The results in Tables 6 and 7 exhibit that Yahoo shopping (alternative $A$ ) obtains the best ranking and selection because it has the highest grey relational degree, and Amazon (alternative $C$ ) should be prioritised for improvement because it has the least grey relational degree. The comparative results present that the proposed approach is better than the traditional method because its grey relational coefficients are not equal to one $\left(\tilde{\gamma}\left(\tilde{x}_{j}^{a s p i r e}, \tilde{x}_{k j}\right) \neq 1\right)$. Moreover, the proposed method can obtain a more realistic grey relational degree, facilitating the formulation of the best improve- 
ment plan for towards achieving the aspiration level in reality; the traditional grey relation analysis (GRA) method can achieve only a relatively optimal result (such as Table 7, grey relational coefficient in traditional method, $\gamma\left(x_{j}^{\max }, x_{k j}\right)$ in each criterion exists one alternative equal one, when $\left.x_{j}^{\max }=\max _{k}\left\{x_{k j} \mid k=1,2,3, \ldots, K\right\}\right)$; so the traditional GRA method cannot be used for performance improvement because its grey relational coefficients are equal to one in each criterion of alternatives. According to the comparison study in Tables 6 and 7, we found very interesting phenomenon as follows. In the traditional GRA/FGRA method, the constant values of $\Delta \max _{j}=\max _{k} \max _{j}\left|\tilde{x}_{j}^{\max } \Theta \tilde{x}_{k j}\right|$ and $\Delta \min _{j}=\min _{k} \min _{j}\left|\tilde{x}_{j}^{\max } \Theta \tilde{x}_{k j}\right|$ are also different with different max-min values of different criteria in alternatives, in other words, it will affect the grey relational degree because there is no common base of evaluation in constant value. The results show that the decision-makers cannot make the accurate strategy. In the proposed modified GRA/FGRA (MGRA/MFGRA) approach, the constant values of $\Delta \max _{j}=\max _{k} \max _{j}\left|\tilde{x}_{j}^{\text {aspired }} \Theta \tilde{x}_{k j}\right|$ and $\Delta \min _{j}=\min _{k} \min _{j}\left|\tilde{x}_{j}^{\text {aspired }} \Theta \tilde{x}_{k j}\right|$ (where $\left.\tilde{x}_{j}^{\text {aspired }}=(4,4,4)\right)$ are stationary, and hold the same common base of evaluation. The results indicate that the new MGRA/MFGRA method is reasonable to use for the selection and ranking of alternatives, and also use for the performance improvement towards reaching the aspiration level. In other words, the traditional GRA/FGRA method cannot be used for performance improvement because its performance gaps existed one in three alternatives. Therefore, the proposed new MGRA/MFGRA approach is better than the traditional GRA/ FGRA method, which can help the decision-makers to make the accurate development and improvement strategies for satisfying the real world situations. According to Table 7, for all alternatives in the proposed method, "perceived security" is the dimension with the minimal grey relational coefficient and should be prioritised for improvement, and it is the easiest to improve. "Privacy protection", which is the criterion with the minimal grey relational coefficient in the "perceived security" dimension, should be prioritised for improvement. The results exhibited that the proposed model, which involves the use of the FINRM and the consideration of interrelationships (i.e., feedback and dependence effects) between criteria and dimensions in fuzzy environment with uncertain information, can help solve m-commerce problems and increase the grey relational coefficients, facilitating the achievement of aspiration level in the era of IoT. This study used the influential factors, the most critical factor, and the minimal grey relational degree as the critical factors to determine the best improvement plan in reality. The following recommendations are made for promoting the performance of m-commerce. The decision-makers should think how to implore enterprises to promote "perceived security $\left(D_{3}\right)$ " as a priority dimension for improvement. Furthermore, the decision-makers can refer to $D_{3}$ for advising their enterprises to prioritise the improvement of "privacy protection $\left(C_{11}\right)$ " for upgrading their perceived security. Accordingly, the decision-makers can refer to the FINRM obtained from the FDEMATEL technique, the fuzzy influence weights obtained from the FDANP, and the grey relational degrees obtained from the MFGRA for improving the dimensions and criteria that are a priority in the improvement model for m-commerce. The results for Yahoo shopping (alternative $A$ ), PChome online 24 hours (alternative $B$ ), and Amazon (alternative $C$ ) exhibited that "perceived security" is the main customer requirement, and therefore, the decision-makers should guarantee "privacy protection" in online transactions to enhance "perceived security". 


\section{Conclusions and remarks}

On the basis of real world relationships, this paper combined the FDEMATEL technique, the FDANP, and MFGRA methods to develop a new hybrid FMADM model that could be utilized to explore and promote $\mathrm{m}$-commerce for satisfying consumer/user needs in the era of IoT. The principal emphasises of this study are as follows. First, a model was constructed for solving decision-making problems related to the improvement of $\mathrm{m}$-commerce, and it could supply the decision-makers with a deep realization of the factors influencing $\mathrm{m}$-commerce improvement. Second, the FDEMATEL technique can be used for constructing a fuzzy influence network relationship for systematic improvement, for solving problems related to interactive relationships in a fuzzy environment with uncertain information, and for overcoming the assumption of independent dimensions and criteria in hierarchic structure. The FDANP method is capable of deriving the fuzzy influence weights to eliminate the time-consuming investigations of the original ANP questionnaires and to address the feedback and dependence problems. Third, the comparatively good result is substituted by the aspiration level to avoid the situation of "choosing the best among inferior alternatives" for satisfying the demands of current competitive markets. The MFGRA approach could convert the fuzzy performance values into fuzzy grey relational coefficients by using the concept of aspiration level to replace traditional "max-min" as the benchmark. The fuzzy grey relational coefficients could enable the decision-makers to increase the relational coefficients in each criterion and dimension for solving the problems of fuzzy decision-making and towards approximating the aspiration level based on the FINRM. The FINRM could support to identify the origins of a problem for their systematic improvement, and therefore, it can support the decisionmakers to realize the causality of fuzzy decision-making problems and establish the best improvement strategy for m-commerce in reality. Fourth, the new hybrid FMADM model could be utilized for not only the selection and ranking, but also the performance improvement towards approximating the aspiration level. The empirical case study demonstrated that the proposed new hybrid FMADM model with MGRA/MFGRA is utility in performing ranking/selection and indicating the improvement direction. The results exhibited that Yahoo shopping (alternative $A$ ) obtained the best ranking and selection because it had the highest grey relational degree. Furthermore, the comparative results exhibited that the proposed method is superior to the traditional method because its grey relational coefficient is not equal to one; moreover, the proposed method can obtain a more realistic grey relational degree. We conclude that the results provide guidance for the decision-makers by identifying the dimension/criterion critical for decision-making and by identifying the best approach for enhancing "perceived security" through "privacy protection" for promoting m-commerce.

Two limitations of this study require further examination. First, a large sample with a strong explanatory power should be used to verify the patterns in the results. Second, the evaluation attributes were adopted from the relevant literature for $\mathrm{m}$-commerce, and the investigations of pre-test questionnaires in practice experience. A dominance-based rough set approach should be used to identify other possible criteria for analysis; such an approach can sort core attributes resulting from longitudinal studies and in-depth interviews. 


\section{References}

Ajzen, I. 1991. The theory of planned behavior, Organizational Behavior and Human Decision Processes 50(2): 179-211. https://doi.org/10.1016/0749-5978(91)90020-T

Aldridge, A.; White, M.; Forcht, K. 1997. Security considerations of doing business via the Internet: cautions to be considered, Internet Research 7(1): 9-15. https://doi.org/10.1108/10662249710159809

Atzori, L.; Iera, A.; Morabito, G. 2010. The Internet of things: a survey, Computer Networks 54: 27872805. https://doi.org/10.1016/j.comnet.2010.05.010

Barnes, S. J. 2002. The mobile commerce value chain: analysis and future developments, International Journal of Information Management 22(2): 91-108. https://doi.org/10.1016/S0268-4012(01)00047-0

Chellappa, P. K.; Pavlou, P. A. 2002. Perceived information security, financial liability and consumer trust in electronic commerce transactions, Logistics Information Management 15(5/6): 358-368. https://doi.org/10.1108/09576050210447046

Chiou, H. K.; Tzeng, G. H. 2001. Fuzzy hierarchical evaluation with grey relation model of green engineering for industry, International Journal of Fuzzy Systems 3(3): 466-475.

Chiu, W. Y.; Tzeng, G. H.; Li, H. L. 2014. Developing e-store marketing strategies to satisfy customers' needs using a new hybrid gray relational model, International Journal of Information Technology \& Decision Making 13(2): 231-261. https://doi.org/10.1142/S0219622014500357

Chong, A. Y. L. 2013a. Predicting m-commerce adoption determinants: a neural network approach, Expert Systems with Applications 40(2): 523-530. https://doi.org/10.1016/j.eswa.2012.07.068

Chong, A. Y. L. 2013b. Mobile commerce usage activities: the roles of demographic and motivation variables, Technological Forecasting and Social Change 80(7): 1350-1359. https://doi.org/10.1016/j.techfore.2012.12.011

Davis, F. D. 1989. Perceived usefulness, perceived ease of use, and user acceptance of information technology, MIS Quarterly 13(3): 319-340. https://doi.org/10.2307/249008

Davis, F. D.; Bagozzi, R. P.; Warshaw, P. R. 1989. User acceptance of computer technology: a comparison of two theoretical models, Management Science 35(8): 982-1003.

https://doi.org/10.1287/mnsc.35.8.982

Deng, J. L. 1982. Control problems of grey system, System and Control Letters 1(5): 288-294. https://doi.org/10.1016/S0167-6911(82)80025-X

Fang, Y.; Qureshi, I.; Sun, H.; McCole, P.; Ramsey, E.; Lim, K. H. 2014. Trust, satisfaction, and online repurchase intention: the moderating role of perceived effectiveness of e-commerce institutional mechanisms, MIS Quarterly 38(2): 407-427. https://doi.org/10.25300/MISQ/2014/38.2.04

Gabus, A.; Fontela, E. 1972. World problems, an invitation to further thought within the framework of DEMATEL. Battelle Geneva Research Centre, Geneva, Switzerland.

Gabus, A.; Fontela, E. 1973. Perceptions of the world problematique: communication procedure, communicating with those bearing collective responsibility (DEMATEL Report No. 1). Battelle Geneva Research Centre, Geneva, Switzerland.

Gefen, D. 2000. E-commerce: the role of familiarity and trust, Omega 28(6): 725-737. https://doi.org/10.1016/S0305-0483(00)00021-9

Gefen, D. 2002. Nurturing clients' trust to encourage engagement success during the customization of ERP systems, Omega 30(4): 287-299. https://doi.org/10.1016/S0305-0483(02)00032-4

Gefen, D.; Karahanna, E.; Straub, D. W. 2003. Trust and TAM in online shopping: an integrated model, MIS Quarterly 27(1): 51-90.

Gefen, D.; Straub, D. W. 2004. Consumer trust in B2C e-commerce and the importance of social presence: experiments in e-products and e-services, Omega 32(6): 407-424.

https://doi.org/10.1016/j.omega.2004.01.006 
Gefen, D.; Wyss, S.; Lichtenstein, Y. 2008. Business familiarity as risk mitigation in software development outsourcing contracts, MIS Quarterly 32(3): 531-551.

Gubbi, J.; Buyya, R.; Marusic, S; Palaniswami, M. 2013. Internet of things (IoT): a vision, architectural elements, and future directions, Future Generation Computer Systems 29(7): 1645-1660. https://doi.org/10.1016/j.future.2013.01.010

Haq, A. N.; Kannan, G. 2006. An integrated approach for selecting a vendor using grey relational analysis, International Journal of Information Technology \& Decision Making 5(2): 277-295. https://doi.org/10.1142/S0219622006001952

Hsu, C. Y.; Chen, K. T.; Tzeng, G. H. 2007. FMCDM with fuzzy DEMATEL approach for customers' choice behavior model, International Journal of Fuzzy Systems 4(4): 236-246.

Huang, J. J.; Tzeng, G. H. 2014. New thinking of multi-objective programming with changeable spaces - in search of excellence, Technological and Economic Development of Economy 20(2): 242-261. https://doi.org/10.3846/20294913.2013.860931

Hu, S. K.; Lu, M. T.; Tzeng, G. H. 2015. Improving mobile commerce adoption using a new hybrid fuzzy MADM model, International Journal of Fuzzy Systems 17(3): 399-413. https://doi.org/10.1007/s40815-015-0054-Z

Kim, C.; Tao, W.; Shin, N.; Kim, K. S. 2010. An empirical study of customers' perceptions of security and trust in e-payment systems, Electronic Commerce Research and Applications 9(1): 84-95. https://doi.org/10.1016/j.elerap.2009.04.014

Kou, G.; Lu, Y.; Peng, Y.; Shi, Y. 2012. Evaluation of classification algorithms using MCDM and rank correlation, International Journal of Information Technology \& Decision Making 11(1): 197-225. https://doi.org/10.1142/S0219622012500095

Leu, F. Y.; Huang, Y. L.; Wang, S. M. 2015. A Secure M-Commerce system based on credit card transaction, Electronic Commerce Research and Applications 14(5): 351-360. https://doi.org/10.1016/j.elerap.2015.05.001

Li, S.; Tryfonas,T.; Li , H. 2016. The Internet of things: a security point of view, Internet Research 26(2): 337-359. https://doi.org/10.1108/IntR-07-2014-0173

Liao, S.; Shao, Y. P.; Wang, H.; Chen, A. 1999. The adoption of virtual banking: an empirical study, International Journal of Information Management 19(1): 63-74. https://doi.org/10.1016/S0268-4012(98)00047-4

Liou, J. J. H.; Tzeng, G. H. 2012. Comments on multiple criteria decision making (MCDM) methods in economics: an overview, Technological and Economic Development of Economy 18(4): 672-695. https://doi.org/10.3846/20294913.2012.753489

Liou, J. J. H. 2013. New concepts and trends of MCDM for tomorrow - in honor of Professor GwoHshiung Tzeng on the occasion of his $70^{\text {th }}$ birthday, Technological and Economic Development of Economy 19(2): 367-375. https://doi.org/10.3846/20294913.2013.811037

Liou, J. J. H.; Chuang, Y. C.; Tzeng, G. H. 2014. A fuzzy integral-based model for supplier evaluation and improvement, Information Sciences 266: 199-217. https://doi.org/10.1016/j.ins.2013.09.025

Liou, J. J. H.; Tamošaitienè, J.; Zavadskas, E. K.; Tzeng, G. H. 2016. New hybrid COPRAS-GMADM model for improving and selecting suppliers in green supply chain management, International Journal of Production Research 54(1): 114-134. https://doi.org/10.1080/00207543.2015.1010747

Lu, M. T.; Tzeng, G. H.; Tang, L. L. 2013. Environmental strategic orientations for improving green innovation performance in fuzzy environment - using new fuzzy hybrid MCDM model, International Journal of Fuzzy Systems 15(3): 297-316.

Lu, M. T.; Hu, S. K.; Tzeng, G. H. 2015. Evaluating the implementation of business-to-business mcommerce by SMEs based on a new hybrid MADM model, Management Decision 53(2): 290-317. https://doi.org/10.1108/MD-01-2014-0012 
Maity, M.; Dass, M. 2014. Consumer decision-making across modern and traditional channels: Ecommerce, m-commerce, in-store, Decision Support Systems 61: 34-46. https://doi.org/10.1016/j.dss.2014.01.008

McKnight, D. H.; Chervany, N. L. 2001. What trust means in e-commerce customer relationships: An interdisciplinary conceptual typology, International Journal of Electronic Commerce 6(2): 35-59. https://doi.org/10.1080/10864415.2001.11044235

McKnight, D. H.; Choudhury, V.; Kacmar, C. 2002. Developing and validating trust measures for ecommerce: an integrative typology, Information Systems Research 13(3): 334-359. https://doi.org/10.1287/isre.13.3.334.81

Ngai, E. W. T.; Gunasekaran, A. 2007. A review for mobile commerce research and applications, Decision Support Systems 43(1): 3-15. https://doi.org/10.1016/j.dss.2005.05.003

Opricovic, S.; Tzeng, G. H. 2003. Defuzzification within a fuzzy multicriteria decision model, International Journal of Uncertainty, Fuzziness and Knowledge-based Systems 11(5): 635-652. https://doi.org/10.1142/S0218488503002387

Peng, Y.; Kou, G.; Wang, G.; Shi, Y. 2011. FAMCDM: a fusion approach of MCDM methods to rank multiclass classification algorithms, Omega 39(6): 677-689. https://doi.org/10.1016/j.omega.2011.01.009

Pynpoo, B.; van Braak, J. 2014. Predicting teachers' generative and receptive use of an educational portal by intention, attitude and self-reported use, Computers in Human Behavior 34: 315-322. https://doi.org/10.1016/j.chb.2013.12.024

Ridings, C. M.; Gefen, D.; Arinze, B. 2002. Some antecedents and effects of trust in virtual communities, Journal of Strategic Information Systems 11(3-4): 271-295. https://doi.org/10.1016/S0963-8687(02)00021-5

Ruan, J.; Shi, Y. 2016. Monitoring and assessing fruit freshness in IOT-based e-commerce delivery using scenario analysis and interval number approaches, Information Sciences 373: 271-295. https://doi.org/10.1016/j.ins.2016.07.014

Saaty, T. L. 1996. Decision making with dependence and feedback: the analytic network process. RWS Publications, Pittsburgh.

Sadeh, N. 2002. M-commerce: technologies, services, and business models. New York: John Wiley and Sons.

Simon, H. A. 1955. A behavioral model of rational choice, The Quarterly Journal of Economics 69(1): 99-118. https://doi.org/10.2307/1884852

Simon, H. A. 1972. Theories of bounded rationality, in C. B. McGuire, R. Radner (Eds.). Decision and Organization. Amsterdam: North-Holland, 161-176.

Su, C. H.; Tzeng, G. H; Hu, S. K. 2016. Cloud e-learning service strategies for improving e-learning innovation performance in a fuzzy environment by using a new hybrid fuzzy multiple attribute decision-making model, Interactive Learning Environments 24(8): 1812-1835. https://doi.org/10.1080/10494820.2015.1057742

Suh, B.; Han, I. 2003. The impact of customer trust and perception of security control on the acceptance of electronic commerce, International Journal of Electronic Commerce 7(3): 135-161.

Taylor, S.; Todd, P. 1995. Decomposition and crossover effects in the theory of planned behavior: a study of consumer adoption intentions, International Journal of Research in Marketing 12(2): 137155. https://doi.org/10.1016/0167-8116(94)00019-K

Tsiakis, T.; Sthephanides, G. 2005. The concept of security and trust in electronic payments, Computers \& Security 24(1): 10-15. https://doi.org/10.1016/j.cose.2004.11.001

Tzeng, G. H.; Chiang, C. H.; Li, C. W. 2007. Evaluating intertwined effects in e-learning programs: a novel hybrid MCDM model based on factor analysis and DEMATEL, Expert Systems with Applications 32(4): 1028-1044. https://doi.org/10.1016/j.eswa.2006.02.004 
Tzeng, G. H.; Huang, J. J. 2011. Multiple attribute decision making: methods and applications. CRC Press, Taylor \& Francis Group, a Chapman \& Hall Book.

Tzeng, G. H.; Huang, J. J. 2013. Fuzzy multiple objective decision making. CRC Press, Taylor \& Francis Group, a Chapman \& Hall Book.

Venkatesh, V.; Morris, M. G.; Davis, G. B.; Davis, F. D. 2003. User acceptance of information technology: toward a unified view, MIS Quarterly 27(3): 425-478.

Vijayasarathy, L. R. 2004. Predicting consumer intentions to use on-line shopping: the case for an augmented technology acceptance model, Information and Management 41(6): 747-762. https://doi.org/10.1016/j.im.2003.08.011

Watson, C.; McCarthy, J.; Rowley, J. 2013. Consumer attitudes towards mobile marketing in the smart phone era, International Journal of Information Management 33(5): 840-849. https://doi.org/10.1016/j.ijinfomgt.2013.06.004

Yang, K. C. C. 2005. Exploring factors affecting the adoption of mobile commerce in Singapore, Telematics and Informatics 22(3): 257-277. https://doi.org/10.1016/j.tele.2004.11.003

Zadeh, L. A. 1975. The concept of a linguistic variable and its application to approximate reasoning, Information Sciences 8(3): 199-249. https://doi.org/10.1016/0020-0255(75)90036-5 